NASA Contractor Report 198520

AIAA-96-2978

\title{
Launch Vehicle and Power Level Impacts on Electric GEO Insertion
}

Steven R. Oleson and Roger M. Myers

NYMA, Inc.

Brook Park, Ohio

August 1996

Prepared for

Lewis Research Center

Under Contract NAS3-27186

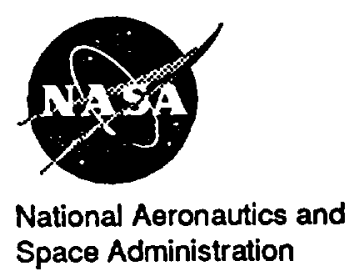





\title{
Launch Vehicle and Power Level Impacts on Electric GEO Insertion
}

\author{
Steven R. Oleson and Roger M. Myers \\ NYMA Inc. \\ NASA Lewis Research Center \\ Brookpark, OH 44142
}

\begin{abstract}
Solar Electric Propulsion (SEP) has been shown to increase net geosynchronous spacecraft mass when used for station keeping and final orbit insertion. The impact of launch vehicle selection and power level on the benefits of this approach were examined for 20 and $25 \mathrm{~kW}$ systems launched using the Ariane 5. Atlas IIAR, Long March, Proton, and Sea Launch vehicles. Two advanced on-board propulsion technologies, $5 \mathrm{~kW}$ ion and Hall thruster systems, were used to establish the relative merits of the technologies and launch vehicles. GaAs solar arrays were assumed. The analysis identifies the optimal starting orbits for the SEP orbit raising/plane changing while considering the impacts of radiation degradation in the Van Allen belts. shading. power degradation, and oblateness. This use of SEP to provide part of the orbit inserion results in net mass increases of $15-38 \%$ and $18-46 \%$ for one to two month trip times, respectively, over just using SEP for 15 years of north/south station keeping. SEP technology was shown to have a greater impact on net masses of launch vehicles with higher launch latitudes when avoidance of solar array and payload degradation is desired. This greater impact of SEP could help reduce the plane changing disadvantage of high latitude launch sites. Comparison with results for 10 and $15 \mathrm{~kW}$ systems show clear benefits of incremental increases in SEP power level, suggesting that an evolutionary approach to high power SEP for geosynchronous spacecraft is possible.
\end{abstract}

\section{INTRODUCTION}

Solar Electric Propulsion (SEP) is being used for station keeping of geosynchronous satellites, including hydrazine arcjets on several Lockheed Martin spacecraft and SPT-100 Hall thrusters on the Russian GALS spacecraft. The next step in the application of electric propulsion, placing the spacecraft into geosynchronous orbit. has been shown to be advantageous. $2,3,4,5,6,7$ Hughes is offering the use of electric propulsion for part of the orbit insertion to increase their 702 spacecraft payload. 8

The continuing urend for geosynchronous spacecraft is towards longer lifetimes, increased masses, higher powers, and increased service bandwidth. For example, the Hughes 702 spacecraft is planned to have a lifetime of 15 years and a power level of $15 \mathrm{~kW} .^{8}$ Higher power spacecraft permit the use of higher performance electric propulsion systems to provide more acceptable orbit transfer mission times. Continued evolution of advanced propulsion systems on geosynchronous satellites will enable continued growth of geosynchronous satellite capability without requiring growth in spacecraft launch mass and will permit continued expansion of communications capability.

Studies by various authors have shown the net mass benefits of using electric propulsion for transfer from various high Earth orbits $2,3,4,5,6$ to geosynchronous Earth orbit (GEO) in order to avoid the long trip times and Van Allen belt radiation damage of low Earth orbit
(LEO) to GEO transfers ${ }^{6}$. In this context, net mass refers to the total spacecraft mass minus the wet propulsion system mass and any power system mass added only for propulsion. In most of the previous studies the SEP starting orbits were not optimized.

The purpose of this paper is to build on the previous work, ${ }^{7}$ which showed the benefits of advanced on-board propulsion technology using optimized SEP starting orbits for the Atlas IIAS, by examining the impact of launch vehicle selection and increased power level on the mission design. This paper describes the mission analyses, propulsion options and optimized trajectory results for missions using five different launch vehicles including the Ariane 5, Atlas IAR, Long March. Proton, and Sea Launch. Two payload power levels, 20 and $25 \mathrm{~kW}$, were assumed available for the electric propulsion orbit transfer. These powers are consistent with expected growth in geosynchronous communications satellite power over the next $5-7$ years.

As in the previous study, the mass impact of replacing some portion of the chemical apogee propulsion system with either a Hall thruster or ion thruster system is established. Arcjet thrusters were not evaluated because previous results showed they were not competitive with the higher $I_{s p}$ systems. ${ }^{7}$ The electric system also performs fifteen years of station keeping. Throughout the study, conservative projections for these propulsion 
systems were used in order to make the results applicable to next generation missions.

\section{MISSION ANALYSIS, OPTIONS AND ASSUMIPTIONS}

\section{Mission Analysis}

The numerical optimization program Solar Electric Propulsion Steering Program for Optimal Trajectory (SEPSPOT) ${ }^{9}$ was used to perform optimal impulsive stage (high thrust) analysis to minimize the SEP transfer time. All that is required for the high thrust portion of the program is a tinal mass for this phase of the mission and an initial impulsive $\Delta \mathrm{V} . \Delta \mathrm{V}$ is the velocity or energy change required for an orbit transfer. The final mass of the impulsive portion is the starting mass for the SEP mission. An impulsive $\Delta V$ was assumed for all the chemical propulsion burns in these analyses. The SEP transfer mission $\triangle V s$ differ from impulsive due to gravity losses associated with continuous thrusting and nontangential steering. ${ }^{10}$

The launch vehicles assumed for these analyses are the Atlas IIAR, Ariane, Atlas IIAR, Long March CZ-3B, Proton, and Sea Launch. (Table 1.). These vehicles represent the next generation of commercially available launch vehicles. The Ariane 5 analysis assumes a dual payload, so for this analysis an equivalent upper stage mass of one-half the actual stage was used for each of the payloads. The results of Atlas IIAR should be representative of potential results for the planned Delta III vehicle. Each launch vehicle is assumed to place the satellite and chemical propulsion systems capable of reaching geosynchronous orbit into a $185 \mathrm{~km}$ circular low earth orbit. This circular orbit, termed parking orbit, has an inclination which varies with launcher based on the vehicle's launch site latitude. (See Table 1.). While most launch vehicles use slightly elliptical parking orbits or go directly to geosynchronous transfer orbit (GTO), the high thrust option of the SEPSPOT program is currently limited to circular starting orbits. 9 Thus the $185 \mathrm{~km}$ circular orbit is used for a SEPSPOT starting point.

To reach geosynchronous orbit each launch vehicle uses its upper stage to perform the perigee burn and inject into GTO. The Atlas $\amalg A R$, Ariane 5, and Long March vehicles then require the satellite to use on-board propulsion to perform the apogee burn, while the Proton and Sea Launch upper stages deliver the satellite payload directly into geosynchronous orbit. Launch range constraints currently force the Proton Block DM upper stage to carry a minimum fuel, ${ }^{11}$ but this is ignored for this analysis. The Sea Launch vehicle can perform either a direct ascent to GEO or GTO. and for this study is assumed to deliver payloads directly to GEO. The Sea Launch vehicle uses the same Block DM upper stage as the Proton but has no offloading limit since its launch range is much less constrained.

The mission cases where the electric propulsion system performs only the station keeping function use the upper stage to place them into GTO and either the onboard chemical system or launch vehicle upper stage to insert them into geosynchronous orbit. The mission cases where a portion of the geosynchronous orbit insertion is performed by the on-board electric propulsion system use the available upper stage fuel or the available on-board chemical fuel in an optimal one or two burn transfer to an optimal SEP starting orbit as shown in Figure 1. The perigee burn portion of this transfer is not necessarily to GTO. In this analysis the on-board chemical fuel or the upper stage fuel normally used for the apogee burn for the GEO insertion. hereafter named the apogee chemical fuel. is incrementally offloaded to allow for a fueled electric propulsion system and additional payload. This apogee chemical fuel is not limited to apogee burns for cases where electric orbit insertion is considered. The results show the trade between adding an electric propulsion system for improved payload and increased transfer time.

The SEPSPOT program determines the required one or two impulsive burns with the allotted upper stage or on-board chemical $\triangle V$ to reach an SEP starting orbit which minimizes the SEP trip time. This SEP starting orbit can have any perigee, apogee, and inclination combination which is achievable with the given impulsive $\Delta V$. This $\Delta V$ is the sum of the remaining $\Delta V$ capability of the upper stage and some portion of the on-board apogee $\Delta \mathrm{V}$ normally carried. This on-board (or upper stage) portion is decreased from the normal loading to the GTO fuel loading to show the trade between increased net mass and increased trip time. To illustrate these trades, Figure 2 shows a variation between the apogee chemical $\Delta V$ and the transter SEP $\Delta V$ for a case using ion thrusters. Note that the upper stage $\Delta V$ is constant while the on-board chemical $\Delta V$ is reduced in increments. The SEP $\Delta \mathrm{V}$, calculated using SEPSPOT, required to replace the on-board chemical $\Delta V$ is greater due to gravity losses. This required SEP $\Delta V$ is further discussed in the results section. Figure 3 shows the mass in the SEP starting orbit versus the available apogee chemical $\Delta V$ for each launch vehicle. Note the higher maximum apogee chemical $\Delta V$ required for the vehicles launched from higher latitudes 10 perform the plane change to $0^{\circ}$ inclination. Also note that the slopes of the Proton and Sea Launch curves are 
greater than the other launch vehicles. This is due to the lack of staging and will be explained below.

The SEP optimization includes the impacts of shading. J2 (Earth oblateness), and solar array degradation due to Van Allen belt radiation. The SEP system parameters, initial power level. $\mathrm{I}_{\mathrm{SF}}$. and efficiency, are fixed in the SEPSPOT program. The SEPSPOT program assumes continuous thrusting except while the spacecraft is in shade. SEPSPOT finds the optimal steering to produce a minimum time trajectory.

The impact of power degradation on the trip time causes SEPSPOT to minimize time spent in the Van Allen belts. As power is degraded, SEPSPOT throttles the thrusters while maintaining the same $I_{\mathrm{sp}}$ and efficiency. While thruster performance normally varies as a function of power level this effect is neglected. This SEPSPOT/SEP system modeling limitation is negligible for the desired short transfer time trajectories since the power degradation is very small. The impacts of non-optimal steering and guidance, navigation, and attitude control limitations are not considered here.

In addition to the transfer, fifteen years of north/south station keeping (NSSK) is assumed for all cases. ${ }^{8}$ While the yearly $\Delta \mathrm{V}$ varies with satellite station longitude. $45.37 \mathrm{~m} / \mathrm{s}$ is chosen as representative. 12 The daily station keeping burn time using electric propulsion is on the order of tens of minutes. The cosine losses encountered by not completing the whole burn instantaneously at the orbit node are small and neglected. Eas//west station keeping requirements are an order-of-magnitude smaller than NSSK requirements and are neglected in these analyses.

\section{SYSTEM ASSUMPTIONS AND MODELING}

\section{On-Board Chemical Propulsion System}

For mission scenarios requiring an on-board chemical propulsion system for all or part of the orbit insertion, an advanced $328 \mathrm{~s} \mathrm{I}_{\mathrm{sp}}$ bipropellant system is assumed. 13 The system has a fixed dry mass of 23 $\mathrm{kg}$ and a tankage fraction of 0.08 . The advanced chemical system is deleted from the spacecraft for those missions where the SEP system takes over directly from the launch vehicle upper stage.

\section{On-Board Electric Propulsion System}

For mission scenarios using on-board SEP for NSSK and, in some cases, orbit insertion functions, $5 \mathrm{~kW}$ xenon Hall thruster 14,15 and ion thruster ${ }^{16}$ technologies are considered. The power level is the power into the power processing unit (PPU). Thrusters operating at this power level have been demonstrated in the laboratory but have not been flight qualified. A 5 $\mathrm{kW}$ ion thruster has been lifetested for 900 hours (38 days). 1.4 kW Hall thrusters, which were developed in Russia, are being qualified for western spacecraft by Space Systems Loral. ${ }^{17} 2.5 \mathrm{~kW}$ ion thruster technology is being flight qualified under the NASA Solar electric propulsion Technology Applications Readiness (NSTAR) program. ${ }^{18.19}$ Throughout this analysis, the same electric propulsion technology is used for both transfer and NSSK functions -- no mixing of electric propulsion technologies is considered.

For the orbit insertion function, the assumed thruster specific impulses are 1850s for the Hall thruster, and 3800 s for the ion thruster. These were selected because they have been demonstrated in ground tests 14,16 - no optimization was performed for the missions studied here. The overall PPU/thruster efficiencies regardless of mission function are 0.47 for the xenon Hall thruster. and 0.63 for the xenon ion thruster. These values are likely conservative as they represent currently available technology.

The electric propulsion system can be divided into four parts: the thruster module, the interface module, the fixed propellant and control module, and the tankage. (See Table 2.). This system definition is adapted from Rawlin. 19 Each thruster module consists of a thruster. gimbals, propellant distribution, and structure; resulting in masses of $9.3 \mathrm{~kg}$ for the Hall thruster module, and $13.8 \mathrm{~kg}$ for the ion thruster module. Each interface module includes PPU, wiring, and thermal system. resulting in specific powers of $9 \mathrm{~kg} / \mathrm{kW}$ for the Hall interface module, and $8.6 \mathrm{~kg} / \mathrm{kW}$ for the ion interface module. The fixed propellant storage mass combined with the single digital control and interface unit is 10.8 kg. A tankage fraction of 0.10 is used for both the Hall and ion thrusters.

Thruster lifetime effects are incorporated by adding extra thrusters when required by the mission. Assumed thruster lifetimes are 4000 hours for the Hall thrusters and 8000 hours for the ion thrusters. PPU lifetime was assumed adequate for both the transfer and station keeping missions.

Fifteen years of north/south spacecraft station keeping (NSSK) is performed by four thrusters, one pair placed on the north face and the other on the south face as shown in Fig 4. These thruster pairs are canted $45^{\circ}$ and $30^{\circ}$ for the Hall thrusters 5 and ion thrusters, 19 respectively, from the vertical to minimize plume interaction with the solar array. The equivalent NSSK 
thruster $\mathrm{I}_{\mathrm{sp}}$ is adjusted for the thruster cant cosine loss as follows: 1308s for the Hall thruster, and $3291 \mathrm{~s}$ for the ion thruster. To pertiom the north/south station keeping either the south or north pair is fired about the appropriate orbit node on the order of tens of minutes. If one thruster fails the opposite set are tasked with all NSSK burns. Four PPUs support the four NSSK thrusters.

For orbit insertion the four NSSK thrusters will be gimbaled to be aft pointing. For the $25 \mathrm{~kW}$ cases an additional electric thruster is added to the aft face of the spacecraft as shown in Figure 4. This additional thruster necessitates using two chemical on-board thrusters on either side of the electric thruster. The transfer thrusters use the available four NSSK PPUs and have an additional PPU added for the extra thruster.

\section{Power System}

The GaAs planar solar arrays which provide payload power in geosynchronous orbit are assumed to provide the $20 \mathrm{~kW}$ or $25 \mathrm{~kW}$ for the thruster operation during the SEP orbit transfer since the payload is inactive during this phase. These power levels were chosen as representative of next generation power levels for geosynchronous communication satellites. ${ }^{l}$ The battery system is assumed to power NSSK thruster operation while the payload uses direct solar array power as suggested by Free. ${ }^{20}$ Extra batteries may be required to support the increase in charge/discharge cycling, but this mass is not determined here. The arrays are assumed to have an equivalent layer of 6 mils fused silica shielding on both sides of the solar array for radiation protection. 12 Since the array is resident on the spacecraft for payload use its mass is not charged to the propulsion system. However, transfer through the Van Allen belts will damage the array. This damaged array mass is charged to the propulsion system at a rate of $16.6 \mathrm{~kg} / \mathrm{kW}$. ${ }^{21}$ Thus the propulsion system is penalized for long transfers through the Van Allen Belts. Radiation damage that may occur to the payload is not assessed.

\section{RESULTS}

\section{SEP Starting Orbits}

Optimal SEP starting orbits determined by SEPSPOT for the Hall thruster. $25 \mathrm{~kW}$ spacecraft with the various launch vehicles are shown in Figures 5-8. The Long March CZ-3B launcher starting orbit results are very similar to the Atlas IIAR's so the CZ-3B's starting orbits are not shown. The results for the other thruster power levels and technologies are similar, suggesting that the optimal SEP starting orbit is dependent mainly upon the parking orbit inclination.

The figures show the starting SEP orbit parameters. including apogee and perigee altitude and inclination. as a function of the available apogee chemical propulsion $\Delta V$. The latter is directly related to the on board or upper stage chemical propulsion fuel loading. The largest apogee chemical $\Delta V$ corresponds to the case in which electric propulsion is not used for the orbit insertion. Only one or two chemical burns are allowed by SEPSPOT. Many cases use a two burn scenario where the apogee is raised above geosynchronous orbit altitude, the perigee is also raised, and some portion of the plane change performed.

For all launchers except Sea Launch. the optimal trajectory results show a steady increase in the amount of inclination change performed by the electric propulsion system as apogee chemical propellant is removed. The Sea Launch result is due to its launch from $0^{\circ}$ inclination. The amount of perigee raising also steadily increases as apogee chemical propellant is removed. As shown in Figure 9, the major difference in the SEP starting orbits is the apogee altitude. For missions starting at high inclinations the apogee is high above geosynchronous altitude, peaking at $90,000 \mathrm{~km}$ for the Proton launch vehicle. Use of these high apogees allows the SEP system to perform the plane change more efficiently. For the Ariane 5 and Sea Launch systems only a slightly higher apogee is used when small amounts of apogee chemical propellant are removed. As more apogee chemical propellant is removed the apogee dips below geosynchronous altitude and the perigee is significantly raised. It is important to note that the optimal SEP starting orbits are never circular and always have apogee altitudes above the most damaging regions of the Van Allen belts.

Figure 2 shows the corresponding required transfer SEP $\Delta \mathrm{V}$ with varying apogee chemical $\Delta \mathrm{V}$ for the Ariane 5 . $25 \mathrm{~kW}$ ion system. Cases 1 to 10 show the trade in chemical and SEP $\Delta V$. As apogee chemical $\Delta V$ capability is replaced by SEP $\Delta V$, the total $\Delta V$ increases due to the gravity losses incurred by the constant thrusting SEP system. Case 10 shows the limit when the GTO to GEO transfer is performed completely by the SEP system and the launch vehicle upper stage. with no apogee chemical system. Comparing cases 10 and $I$ clearly shows the increased total $\Delta V$ required. However, the higher $I_{S P}$ of the SEP system more than offsets this increased $\Delta V$ by significantly reducing the total fuel mass. This is shown by the net mass advantage in the next sections. 


\section{Figures of Merit}

The figures of merit of the advanced propulsion systems in this study are the net mass delivered and the SEP transfer time. As mentioned above, net mass refers to the usable satellite mass once the wet propulsion system and any damaged array are removed. The added net mass can be used for additional payload to increase revenue. Transfer times above 180 days are not shown.

\section{Propulsion System Performance}

The baseline apogee chemical system consists of either a $328 \mathrm{~s} \mathrm{I}_{\mathrm{sp}}$ on-board chemical system which delivers the spacecraft to geosynchronous orbit for the Ariane 5 , Atlas IIAR. and CZ-3B launchers, or the upper launch vehicle stage for the Sea Launch, and Proton launchers. In the latter cases no on-board propulsion system is required. The baseline NSSK system is the ion or Hall system. The advanced orbit insertion options are compared to these NSSK baselines. Previous work ${ }^{7}$ compared the performance of current state-of-art onboard chemical and arcjet NSSK systems with advanced propulsion systems. The net masses achievable with the baseline chemical system performing the entire orbit insertion and the ion or Hall thrusters performing the NSSK are shown in the net mass performance figures in the following sections. These cases are designated the Ion NSSK or Hall NSSK in the figures.

The next sections present the analysis results for each of the chosen launch vehicles. Because of the significant simplifying assumptions that had to be made in the launch vehicle performance. the results should not be used to compare launch vehicles but rather to establish the relative benefits of advanced propulsion for the different launchers.

\section{Atlas IIAR}

Figure 10 shows a plot of net mass versus SEP transfer time for the 20 and $25 \mathrm{~kW}$ Atlas IIAR launched spacecraft. Also shown is the baseline mission in which the orbit transfer is completed by the upper stage and on-board chemical system and the NSSK is performed using SEP. For the baseline missions, the Ion NSSK system delivers a greater net mass than the Hall NSSK due to higher $I_{\text {sp }}$ and less restrictive cant angle. While NSSK burns are longer for the ion thrusters the impact is assumed minimal.

Figure 10 shows that the net mass is greatly enhanced by modifying the electric propulsion system to provide part of the orbit transfer. Both the ion and Hall systems deliver similar performance, though the ion system outperforms the Hall systems for the shorter transfer times. The net mass gains achieved over the Ion and
Hall NSSK baselines range from $15 \%$ to $25 \%$ for the $20 \mathrm{~kW}$ spacecraft to $18 \%$ to $28 \%$ for the $25 \mathrm{~kW}$ spacecraft for transfer times of one to two months. For these short transfers, where the apogee chemical system is providing most of the $\Delta \mathrm{V}$. the radiation damage is small, and the net mass gain increases quickly as the allowable SEP transfer time is increased. For transfer times between 70 and 120 days the $25 \mathrm{~kW}$ ion thruster spacecraft array experiences significant array degradation, resulting in higher net masses using the Hall thruster for trip times longer than 70 days. The Hall thruster cases incur radiation damage for trip times roughly two weeks shorter than the ion systems due to the higher thrust of the Hall system and the resulting lower starting orbit for a given trip time. The same comparison is true for the $20 \mathrm{~kW}$ spacecraft but at longer trip times. The array degradation is illustrated in Figure 11 , which shows the array power degradation as a function of SEP transfer time. Each curve shows a region of severe degradation with the impact leveling out at longer trip times.

For very low trip times ( 2 weeks), the primary effect of system power level arises from the requirement of an additional thruster at $25 \mathrm{~kW}$ which is not needed at 20 $\mathrm{kW}$. Because the four thruster NSSK system is also used for the orbit insertion mission, net mass gains begin immediately for the $20 \mathrm{~kW}$ case. The added thruster mass for the $25 \mathrm{~kW}$ case necessitates additional transfer time to overcome the dry mass penalty. If reuse of the orbit insertion system for the NSSK mission is not desirable then four additional thrusters must be added. This would reduce the advantage of the ion and Hall net mass gains for all the launch vehicle cases by roughly $70 \mathrm{~kg}$ and $63 \mathrm{~kg}$, respectively.

The benefits of using SEP for GEO insertion are not limited to directly increasing the net mass, but also include the added flexibility of accommodating spacecraft growth during design and production merely by removing some of the apogee chemical propellant and adding some SEP propellant. Thus, by designing the SEP fuel tanks for extra fuel. substantial net mass flexibility can be attained at the cost of slightly increased trip time.

To further illustrate the relative impacts of SEP on the orbit insertion and NSSK portions of the mission, Figure 12 shows the impact of performing only the GEO insertion using SEP, without the additional impact of the NSSK. By contrast to the combined NSSK and orbit insertion cases, in this case the Hall thruster outperforms the ion thruster technology for all trip times. This is due to the absence of the $681 \mathrm{~m} / \mathrm{s}$ 
station keeping requirement. For NSSK the higher $\mathrm{I}_{\mathrm{Sp}}$ ion thrusters are allowed to make a longer, more fuel efficient burn (neglecting battery depth of discharge impacts). The higher thrust Hall system out pertorms the ion system for a fixed trip time because of the increased offloading of on-board chemical propellant. These results demonstrate the existence of an optimal thruster $I_{\text {sp }}$ for a fixed transfer time and power level resulting from the trade-off between offloading chemical propellant versus decreasing the SEP propellant mass. If NSSK is included and the thruster is constrained to one $I_{s p}$, then the optimal $I_{s p}$ is higher. Alternatively, a variable $I_{s p}$ thruster could use optimal $I_{s p} s$ for the orbit transfer and as high as possible $I_{\mathrm{sp}}$ for the station keeping. This station keeping $I_{s p}$ would be limited by burn time and the battery system impacts. Both Hall and ion thrusters have variable $I_{s p}$ capability, and further work is needed to evaluate the optimum $I_{\text {sp }}$

The impact of using higher power systems is illustrated in Figure 13. Work performed in $1995^{7}$ on 10 and 15 kW spacecraft are included. While there are small differences in the assumed system characteristics. the impacts resulting from higher power, more efficient. higher $I_{\text {sp }}$ thrusters are clear: for a given transfer time, the higher power systems deliver substantially more net mass to GEO. Alternatively, similar net mass increases can be gained for quicker, and perhaps more acceptable. transfer times. This clearly shows the potential for evolutionary growth to higher power SEP systems, with increased benefits accrued for each increase in available power level.

\section{Long March CZ-3B}

The behavior of the results for the CZ-3B is similar to those for the Atlas IIAR due to the similarity in launch site latitude (and thus parking orbit inclination), and upper stage and apogee chemical system performance. Figure 14 shows the net mass benefit for the CZ-3B, with essentially identical behavior, though larger magnitudes, than those shown for the Atlas IIAR in Figure 10. As shown in Figure 15, the array power degradation is also similar to the Atlas IIAR case.

\section{Ariane 5}

The dual payload capability of the Ariane 5 launcher places two spacecraft at the same apogee chemical starting orbit. The two spacecraft must thus have equivalent overall orbit raising capability. For this study, both spacecraft were assumed identical with the same SEP starting orbits, and the calculated net mass increases apply to both. Launches of non-identical spacecraft could easily be accommodated by appropriately sizing the apogee chemical and SEP systems and allowing for different orbit insertion times. These options might be used to significantly increase launch vehicle flexibility.

Results for the assumed Ariane 5 scenario are shown in Figure 16 for both the 20 and $25 \mathrm{~kW}$ systems. Both ion and Hall thrusters result in significant net mass increases for both spacecraft on the launcher. As with the Atlas IIAR and CZ-3B launch vehicles. the net mass gains achieved with either of the advanced SEP technologies range from 15 to $25 \%$ for the $20 \mathrm{~kW}$ spacecraft to 18 to $28 \%$ for the $25 \mathrm{~kW}$ spacecraft for transfer times of one to two months. However, because of the lower latitude launch site and the resulting reduced plane change requirement. the overall orbit insertion $\Delta V$ which occurs outside of the most damaging portions of the belts is lower, which limits the benefits from advanced propulsion. Substantial radiation degradation occurs for 20 to 30 day insertion times using the Hall system and at 30 to 40 days for the ion systems as shown by Figure 17. This result may limit the SEP benefit to a net mass increase of 15 to $20 \%$ unless payload shielding is included.

\section{Proton}

The impact of electric propulsion for Proton payloads is significant. Figure 18 shows net mass increases for the Proton launch vehicle using ion or Hall thrusters for NSSK and orbit insertion. The net mass is improved by $\sim 20 \%$ for just two weeks of transfer. One month trip times provide gains of 30 to $38 \%$ and two month transfers provide 40 to $46 \%$. A large portion of the increased net mass is due to the lack of staging with the Proton launcher: not only is propellant offloaded but so is the requirement to take the relatively heavy Proton upper stage to geosynchronous orbit. One advantage of using the Block DM upper stage to deliver the payload directly to GEO is that it avoids the requirement of an on-board chemical propulsion system capable of making a $-50^{\circ}$ plane change. Additionally, the absence of an on-board chemical system lightens the geosynchronous system mass and reduces the NSSK requirements. Degradation encountered during the Proton SEP trajectories is shown in Figure 19.

By contrast to the Atlas IIAR, CZ-3B, and Ariane 5, the Hall technology outperforms the ion technology for the Proton launch vehicle. This is due mainly to the larger increases in starting mass as apogee propellant is unloaded - the heavy Block DM stage is left in a lower orbit (See Figure 3). Thus, while the Hall technology delivers a lower mass fraction than the ion technology for a given apogee chemical $\Delta V$, its higher thrust permits a lower starting orbit for a given transfer time. 
The lower starting orbit more than offsets the effects of the lower $I_{s p}$.

\section{Sea Launch}

The Sea Launch rocket can deliver payloads either to GTO or GEO. To facilitate comparisons with the Ariane 5 and the Proton, missions going directly to GEO were analyzed in this study. Thus, upper stage propellant offloading was directly traded against SEP insertion time, without the addition of an on-board chemical propulsion system.

Figure 20 shows large net mass increases similar to those obtained using the Proton launch vehicle. Again the Hall technology is superior due to the lack of staging discussed in the Proton section. Roughly $25 \%$ to $40 \%$ increases in net mass over cases considering only NSSK are possible for one and two month trip times, respectively. As Figure 21 shows, severe power degradation occurs at 30 to 60 days depending on SEP technology and power level. Net mass gains similar to the Ariane 5 are expected for cases in which the Sea Launch delivers its payload to GTO due to the addition of staging.

\section{Launch Vehicle Comparisons}

Comparison of the net mass increases from SEP orbit insertion between the launch vehicles reveals that the launchers requiring greater plane changes can offload more apogee chemical $\Delta V$ without encountering severe radiation degradation. These degradation regions occur for apogee chemical $\Delta V \mathrm{~s}$ below approximately $850 \mathrm{~m} / \mathrm{s}$ for the Ariane 5 and Sea Launch cases, $1000 \mathrm{~m} / \mathrm{s}$ for the Atlas IIAR and CZ-3B cases, and $1300 \mathrm{~m} / \mathrm{s}$ for the Proton vehicle as shown in Figure 22. Thus $650 \mathrm{~m} / \mathrm{s}$ (Ariane 5 and Sea Launch), $800 \mathrm{~m} / \mathrm{s}$ (Atlas ILAR and $\mathrm{CZ}-3 \mathrm{~B}$ ), and $1050 \mathrm{~m} / \mathrm{s}$ (Proton) of apogee chemical $\Delta V \mathrm{~s}$ can be offloaded with minimal degradation impact. Figure 23 illustrates the power degradation factor as a function of SEP starting orbit perigee. The launch vehicles starting at the higher inclinations suffer less degradation for a given starting orbit perigee, permitting a lower starting perigee altitude for these vehicles for a given degradation. Assuming that the severe portions of the van Allen belts are to be avoided, the possible net mass gains are greater for the higher latitude launch site vehicles, while considering the impact of the lack of staging on the Proton and Sea Launch results. With a one to two month transfer time the launch vehicle playing field could be leveled somewhat.

For all launch vehicles and for a fixed transfer time the Hall thruster provides a larger net mass increase than the ion thruster for the orbit insertion portion of the mission. As discussed earlier in the Atlas IIAR section. this results from. for the same transfer time. the lower $\mathrm{I}_{\mathrm{sp}}$, higher thrust of the Hall technology, which permits a lower SEP starting orbit perigee than possible with the higher $I_{\mathrm{sp}}$, lower thrust ion thruster. However, if the NSSK portion of the mission utilizes the same thrusters, then the ion technology provides the greatest benefit for the Ariane 5, Atlas IIAR. and CZ-3B as a result of the higher total mission $\Delta V$ and the longer burn times permitted for NSSK in the analysis.

\section{CONCLUSIONS}

The use of high power ion and Hall electric propulsion to perform both the north/south station keeping and part of the orbit transfer was examined for GEO spacecraft launched using the Ailas IIAR, Ariane 5. Long March. Sea Launch and Proton launch vehicles. Spacecraft power levels of 20 and $25 \mathrm{~kW}$, consistent with expected growth in GEO communication satellites, were examined to establish the impacts of higher power systems. For the cases studied, net mass increases of 15 to $38 \%$ for one month and 18 to $46 \%$ for two month transfer times are possible compared to the use of the SEP technology for NSSK alone. Even two week transfers can provide significant benefits. For similar transfer times, higher power levels provided greater net mass gains than previous results for 10 and $15 \mathrm{~kW}$ powers, showing the potential benetits of evolutionary growth in electric propulsion power level.

Predicted trajectories show that for each launch vehicle there is a different minimum chemical apogee fuel loading required to avoid the more damaging portions of the radiation belts. Results show that the greater the inclination change required. the greater potential chemical propellant offloading possible without notable radiation degradation to the spacecraft. Thus, SEP technology can have a greater impact on launch vehicles with higher launch latitudes when avoidance of solar array and payload degradation is desired. This greater impact of SEP could help reduce the plane changing disadvantage of high latitude launch sites.

The results show that the lower $\mathrm{I}_{\mathrm{sp}}$, higher thrust. Hall thruster delivers larger net masses than ion for a given transfer time. However, if the orbit insertion thrusters are also used for NSSK. the increased $\Delta V$ and unconstrained NSSK burn times result in higher net spacecraft masses for the ion thruster technology with some launchers. These results indicate that there is an optimal combined mission $I_{s p}$ depending on years of NSSK, magnitude of SEP orbit insertion. power level. and desired SEP insertion time. Current research in ion 
and Hall thrusters has shown the ability for both to be run at higher (Hall) and lower (ion) $I_{\mathrm{sp}} \mathrm{s}$. Other alternatives include using a variable $I_{s p}$ thruster or two thruster types, one for the orbit raising portion of the mission and one for the NSSK. The latter scenario, however, would preclude using the orbit raising thrusters for the NSSK miscion.

\section{Acknowledgments}

Research tor this paper was done at NASA Lewis Research Center's Advanced Space Analysis Office (Contract NAS3-27186). We are indebted to Timothy Wickenheiser, Brian Beaver, and John Riehl for their insightful contributions to this paper.

\section{References}

1. Wilson, A.. Lane's Space Directory. Tenth Edition 1994-95 1994 Jane's Information Group Ltd., Sentinel House. Surrey, UK, pp. 333.312.

2. Oleson, S.R. , Curran. F.M., Myers, R.M., "Electric Propulsion For Geostationary Orbit Insertion", NASA TM106942. August, 1995.

3. Porte. F.. et al.. "Benefits of Electric Propulsion for Orbit Injection of Communication Spacecraft", Paper AIAA $92-$ 1955. March. 1992.

4. Spitzer. A. . 'Near Optimal Transfer Orbit Trajectory using Electric Propulsion', Paper AAS-95-215, Feb. 1995.

5. Vaughan. C.E., Cassady, R.J., “'AAn Updated Assessment of Electric Propulsion Technology for Near-Earth Space Missions", Paper ALAA-92-3202, July, 1992.

6. Free, B. , "'High Altitude Orbit Raising with On-Board Electric Power”, Paper IEPC-93-205, Sept. 1993.

7. Oleson. S.R., Myers, R. M., "Advanced Propulsion for Geostationary Orbit Insertion and North-South Station Keeping", NASA TM-107018, AIAA-95-2513, 31 st JPC, July 1995.

8. “" Hughes Unveils HS 702 Design", Aviation Week and Space Technology, p.27, Oct. 9. 1995

9. Sackett. L.L., et al., "Solar Electric Geocentric Transfer with Attitude Constraints: Analysis", NASA CR-134927, Aug, 1975.

10. Edelbaum, T.N. “Propulsion Requirements for Controllable Satellites", ARS Joumal, Aug 1961, pp. 1079-1089.

11. "Proton Launch Vehicle and Launch Services: User's Guide". Rev. 2, Issue 1, International Launch Services, San Diego, CA, Dec. 1995.

12. Agrawal. B.N. Design of Geosynchronous Spacecraft First Edition, Prentice-Hall, Inc. Englewood Cliffs, NJ, pp. 8588.

13. Myers, R.M., et al., "Small Satellite Propulsion Options", NASA TM-106701, AJAA Paper 94-2997, June 1994.

14. Sankovic, J.M., Haag. T.W., and Manzella. D.H., "Performance Evaluation of a $4.5 \mathrm{~kW}$ SPT Thruster," IEPC-95-30. Proceedings of the 24th International Electric Propulsion Conference, Moscow, Russia, Sept. 1995.

15. Petrosov, V.A. et al., "Investigation $4.5 \mathrm{~kW}$ High Efficiency Hall-Type T-160 Electric Thruster," IEPC-95-031, Proceedings of the 24th International Electric Propulsion Conference, Moscow, Russia, Sept. 1995.

16. Patterson, M.J. and Verhey, T.R., “ 5-kW Xenon Ion Thruster Lifetest," AIAA Paper 90-2543, July 1990, see also NASA TM 103191

17. Day, M., et al.. "SPT-100 Subsystem Qualification Status," AIAA Paper 95-2666, July 1995.

18. Stephenson, R.R., "Electric Propulsion Development and Application in the United States, IEPC-95-1. Proceedings of the 24th International Electric Propulsion Conference, Moscow. Russia, Sept. 1995.

19. Rawlin, V.K., and Majcher, G.A., "Mass Comparisons of Electric Propulsion Systems for NSSK of Geosynchronous Spacecraft," AIAA Paper-91-2347, June 1991.

20. Free, B.A. "North-South Stationkeeping with Electric Propulsion Using Onboard Battery Power", COMSAT Laboratories, 1980

21. Pollard, J.E., et al, "Electric Propulsion Flight Experience and Technology Readiness", AIAA Paper 93-2221, 29th

JPC. June 1993

22. Cox, S., et.. al., "Sea Launch Project", LAF-95-V.3.01, 46th Internationally Astronautics Congress, Oslo, Norway, Oct. 1995.

23. Isakowitz. S.J., Samella, J.. “ International Reference Guide to Space Launch Systems", 2nd edition, American Institute of Aeronautics and Astronautics, Washington. DC.

24. "Lockheed Martin Raises the Stakes in Launch Competition". Space News, p. 32, Nov. 13-26, 1995 


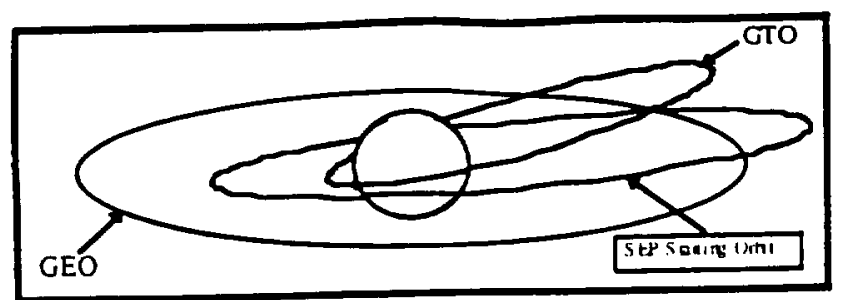

Figure 1 Mission Orbits

Table I Launch Vehicle Parameters for Impulsive GEO Mission

\begin{tabular}{|c|c|c|c|c|c|}
\hline $\begin{array}{l}\text { Launch } \\
\text { Vehicle }\end{array}$ & $\begin{array}{l}\text { Ariane } 5 \\
\text { Ref. } 23 \\
\end{array}$ & \begin{tabular}{c|} 
Aclas \\
IIAR \\
Ref. 24 \\
\end{tabular} & $\begin{array}{l}\text { CZ-3B } \\
\text { Ref. } 23 \\
\end{array}$ & \begin{tabular}{|l|} 
Proton \\
Ref. 23 \\
\end{tabular} & $\begin{array}{c}\text { Sea } \\
\text { Launch } \\
\text { Ref. 22 } \\
\end{array}$ \\
\hline $\begin{array}{c}\text { Perigee } \\
\text { Burn }\end{array}$ & & & & & \\
\hline \begin{tabular}{c|} 
Park Orbit \\
alt.fincl.
\end{tabular} & $\underset{7^{\circ}}{185 \mathrm{~km}}$ & $\begin{array}{c}185 \mathrm{~km} / \\
28.5^{\circ}\end{array}$ & $\begin{array}{c}185 \mathrm{kmv} \\
28.5^{\circ}\end{array}$ & $\mid \begin{array}{c}185 \mathrm{~km} / \\
51.6^{\circ}\end{array}$ & $\begin{array}{c}185 \mathrm{~km} / \\
0^{\circ}\end{array}$ \\
\hline $\begin{array}{c}\text { Upper } \\
\text { Stage } \\
\text { Impulsive }\end{array}$ & 2459 & 2470 & 2470 & 2498 & 2459 \\
\hline$\Delta V(\mathrm{~m} / \mathrm{s})$ & 324 & 449 & 440 & 361 & 361 \\
\hline $\begin{array}{c}{ }^{2} \text { Initial Mass } \\
(\mathrm{kg})\end{array}$ & 8673 & 10200 & 13295 & 21642 & 15813 \\
\hline$\left|\begin{array}{c}\text { Final Mass } \\
(\mathbf{k g})\end{array}\right|$ & 4000 & 5820 & 7500 & 10687 & 7895 \\
\hline $\begin{array}{c}\text { Fuel Mass } \\
(\mathrm{kg})\end{array}$ & 4673 & 4380 & 5795 & 10954 & 7918 \\
\hline $\begin{array}{c}\text { Upper } \\
\text { Stage } \\
\text { Separated } \\
\text { Mass }(k g) \\
\end{array}$ & 1015 & 2000 & 3000 & 3300 & 3100 \\
\hline $\begin{array}{c}\text { Separate } \\
\text { Upper } \\
\text { Stage? }\end{array}$ & yes & yes & yes & no & no \\
\hline $\begin{array}{c}\text { Apogee } \\
\text { Burn }\end{array}$ & & & & & \\
\hline \begin{tabular}{|c|} 
GTO \\
inclination
\end{tabular} & $7^{\circ}$ & $27^{\circ}$ & $27^{\circ}$ & $48.8^{\circ}$ & $0^{\circ}$ \\
\hline $\begin{array}{c}\text { Apogee } \\
\text { Impulsive } \\
\Delta V\end{array}$ & 1503 & 1805 & 1805 & 2353 & 1479 \\
\hline$I_{\text {sp }}$ & 328 & 328 & 328 & 361 & 361 \\
\hline$\left|\begin{array}{c}\text { Initial Mass } \\
(\mathrm{kg}) \\
\text { Fin Mass }\end{array}\right|$ & 2985 & 3820 & 4500 & 10687 & 7895 \\
\hline $\begin{array}{c}\text { final Mass } \\
(\mathrm{kg})\end{array}$ & 1871 & 2180 & 2568 & 5500 & 5200 \\
\hline $\begin{array}{c}\text { Fuel Mass } \\
\text { (kg) }\end{array}$ & 1114 & 1640 & 1932 & 5187 & 2695 \\
\hline $\begin{array}{c}\text { Net Mass in } \\
\text { GEO }\end{array}$ & 1871 & 2180 & 2568 & 2200 & 2100 \\
\hline \begin{tabular}{|c} 
TOTAL \\
Mission \\
Impulsive \\
$\Delta \mathrm{V}$ \\
$(\mathrm{m} / \mathrm{s})$ \\
\end{tabular} & 3962 & 4274 & 4274 & 4850 & 3937 \\
\hline
\end{tabular}

\section{Mission $\triangle \mathrm{V}$ Breakdowns for Arianes Ion, $25 \mathrm{~kW}$}

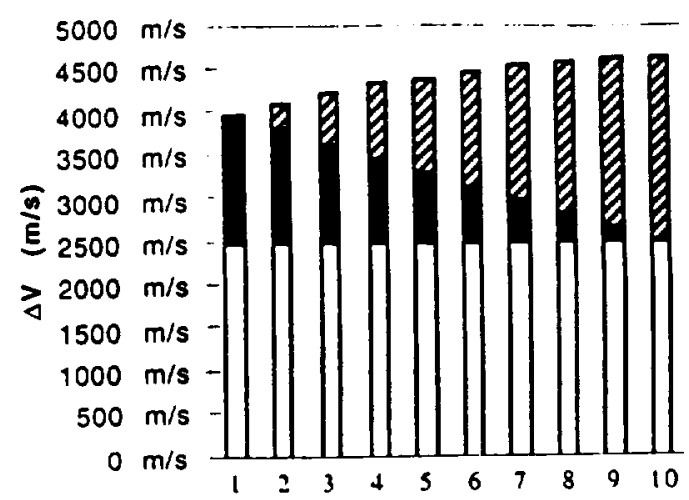

Case

a Upper Stage Chemical $\Delta V$ Apogee Chemical $\Delta V$ - Insertion SEP $\Delta V$

Figure 2 Mission $\triangle \mathrm{V}$ Breakdown vs. Case -- 5. Ion 25 kW Class GEO Satellite

Table 2 SEP Propulsion System Parameters

\begin{tabular}{|c|c|c|}
\hline $\begin{array}{c}\text { Propulsion System } \\
\text { Parameters }\end{array}$ & Xenon Hall Thruster & Xenon Ion Thruster \\
\hline PPU Input Power & $5 \mathrm{~kW}$ & $5 \mathrm{~kW}$ \\
\hline$I_{s p}$ & $1850 \mathrm{~s}$ & $3800 \mathrm{~s}$ \\
\hline $\begin{array}{c}\text { Overall Efliciency } \\
\text { (PPU \& Thruster) }\end{array}$ & 0.47 & 0.63 \\
\hline Tankage traction & 0.10 & 0.10 \\
\hline Life at Power Level & 4.000 hours & 8.000 hours \\
\hline \begin{tabular}{|c|} 
Cant Angle tor \\
NSSK \\
\end{tabular} & $45^{\circ}$ & $30^{\circ}$ \\
\hline Equivalent Cant $\mathrm{I}_{\mathrm{sp}}$ & $1308 \mathrm{~s}$ & $3291 \mathrm{~s}$ \\
\hline Thrust Module & & $8 \mathrm{~kg}$ \\
\hline $\begin{array}{l}\text { Thruster } \\
\text { Gimbals }\end{array}$ & $\frac{7 \mathrm{~kg}}{34 \% \text { of Thruster }}$ & $\frac{8 \mathrm{~kg}}{34 \% \text { of Thruster }}$ \\
\hline$\frac{\text { Simoals }}{\text { Structure }}$ & $\begin{array}{l}31 \% \text { of Gimbals. } \\
\text { Thrusters, \& Prop. } \\
\text { Distribution }\end{array}$ & $\begin{array}{l}31 \% \text { of Gimbals. } \\
\text { Thrusters. \& Prop. } \\
\text { Distribution }\end{array}$ \\
\hline $\begin{array}{c}\text { Propellant } \\
\text { Distribution. }\end{array}$ & $3.3 \mathrm{~kg} / \mathrm{Thruster}$ & $3.3 \mathrm{~kg} / \mathrm{Thruster}$ \\
\hline \begin{tabular}{|l|} 
Total Thruster + \\
Gimbals + Support \\
+ Propellant Dist. \\
\end{tabular} & $11.3 \mathrm{~kg} / \mathrm{thruster}$ & $13.8 \mathrm{~kg} /$ thruster \\
\hline Interface Module & & \\
\hline PPU. cabling & $6.2 \mathrm{~kg} / \mathrm{kWe}$ & $5.7 \mathrm{~kg} / \mathrm{kWe}$ \\
\hline $\begin{array}{l}\text { Thermal Sys. (92\% } \\
\text { PPU) }\end{array}$ & $31 \mathrm{~kg} / \mathrm{kWt}$-disp. & $31 \mathrm{~kg} / \mathrm{kW}$-disp. \\
\hline Structure & $\begin{array}{l}4 \% \text { of Interface } \\
\text { components }\end{array}$ & $\begin{array}{l}4 \% \text { of Interface } \\
\text { components }\end{array}$ \\
\hline $\begin{array}{c}\text { Total PPU + } \\
\text { Cabling + Thermal }\end{array}$ & $9.0 \mathrm{~kg} / \mathrm{kWe}$ & $8.6 \mathrm{~kg} / \mathrm{kWe}$ \\
\hline $\begin{array}{l}\text { Fixed Propellant } \\
\text { Storage and DCIU }\end{array}$ & $10.8 \mathrm{~kg}$ & $10.8 \mathrm{~kg}$ \\
\hline
\end{tabular}




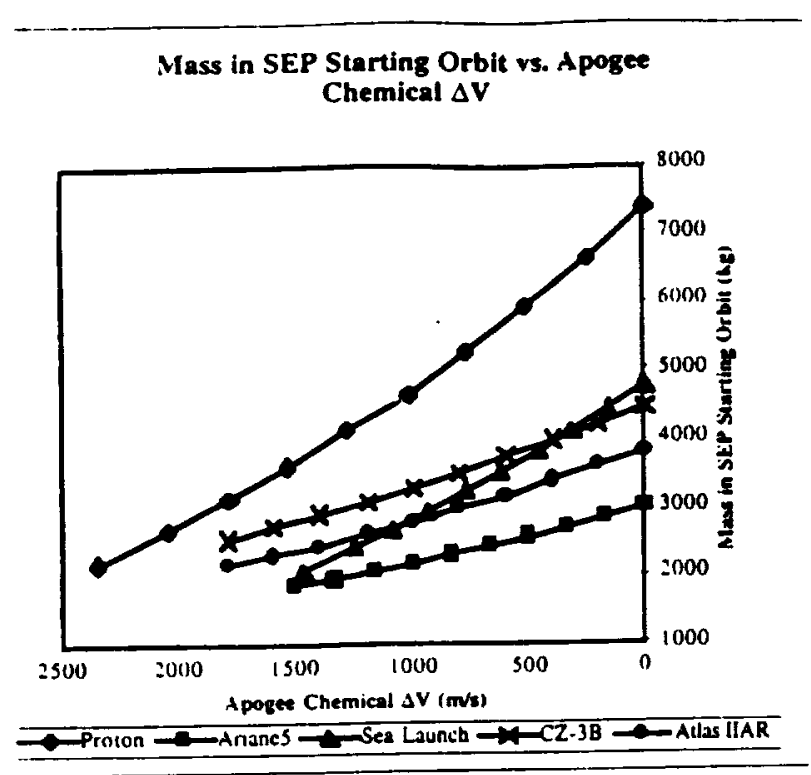

Figure 3 Mass in SEP Starting Orbit vs. Apogee Chemical $\Delta V$ for Various Launch Vehicles

Optimal EP Starting Orbit vs. Apogee Chemical $\Delta V$ Capability: Arianes Hall.25kW

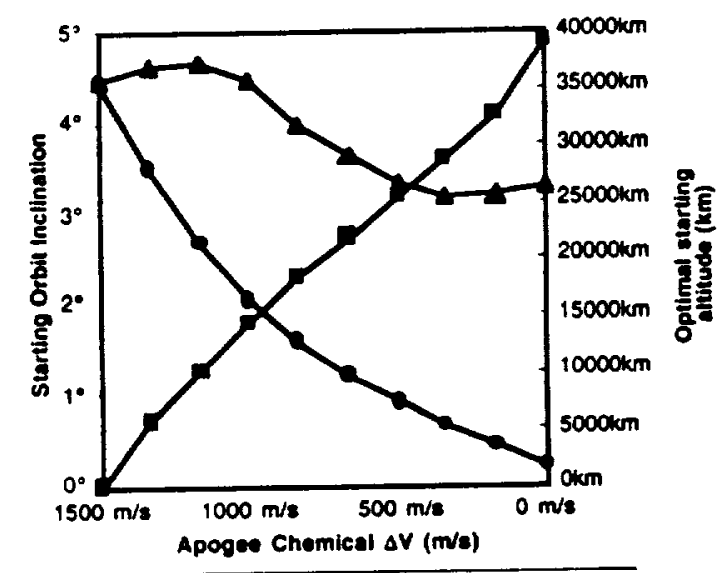

-Apogee Alitude $\rightarrow$ Penges Altude $\rightarrow$-Inctination

Figure 5 Optimal SEP Starting Orbit vs. Apogee Chemical $\Delta V$--Ariane 5, Hall $25 \mathrm{~kW}$ Class GEO Satellite

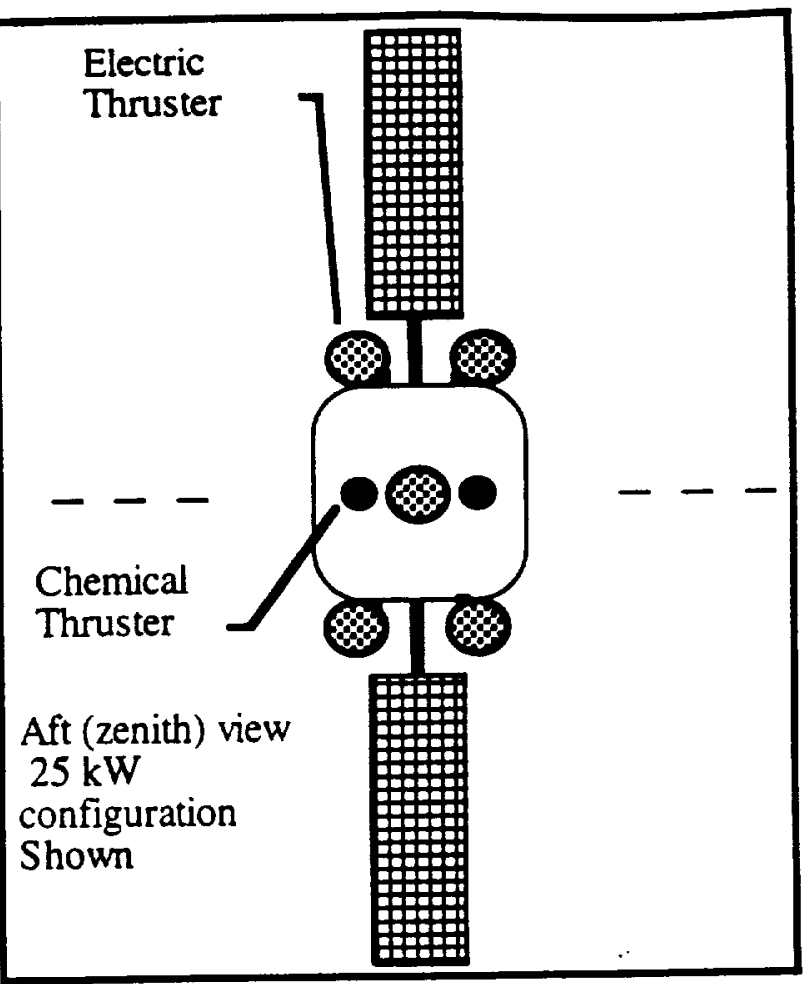

Figure 4 Potential Thruster Placement

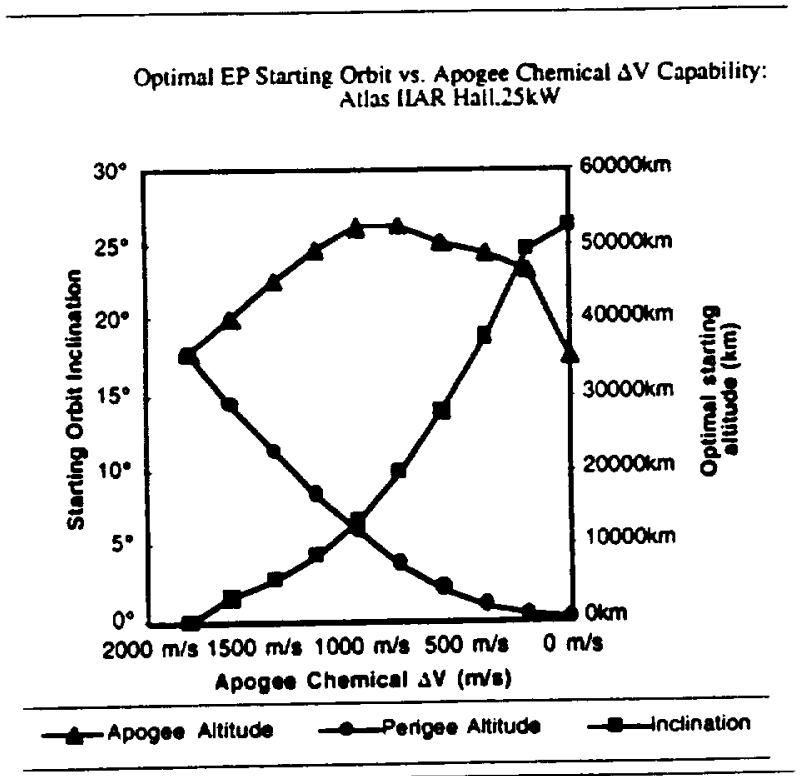

Figure 6 Optimal SEP Starting Orbit vs. Apogee Chemical $\Delta V$--Atlas IIAR, Hall 25 kW Class GEO Satellite 
Opumal EP Staring Orbit vs. Apogee Chemical $\Delta V$ Capability: Proton Hall.25kW

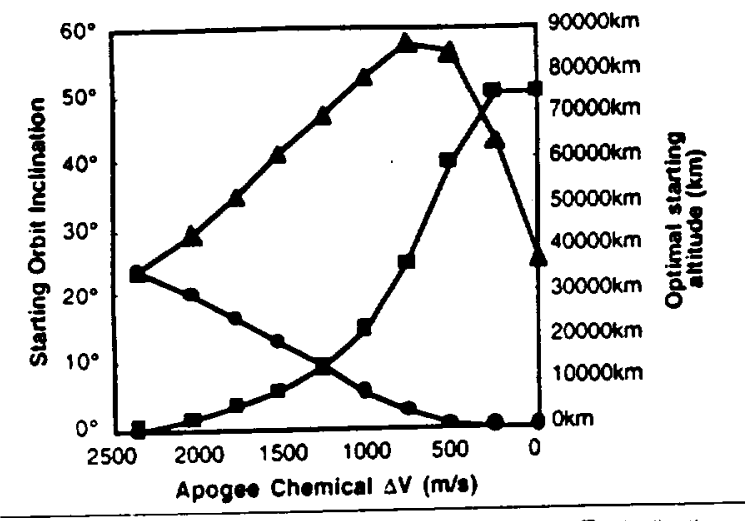

-Apogee Altitude - - Perigee Altitude anclination

Figure 7 Optimal SEP Starting Orbit vs. Apogee Chemical $\Delta V$--Proton. Hall $25 \mathrm{~kW}$ Class GEO Satellite

Optimal EP Starting Orbit vs. Apogee Chemical $\Delta V$ Capability Sea Launch Hall.25kW

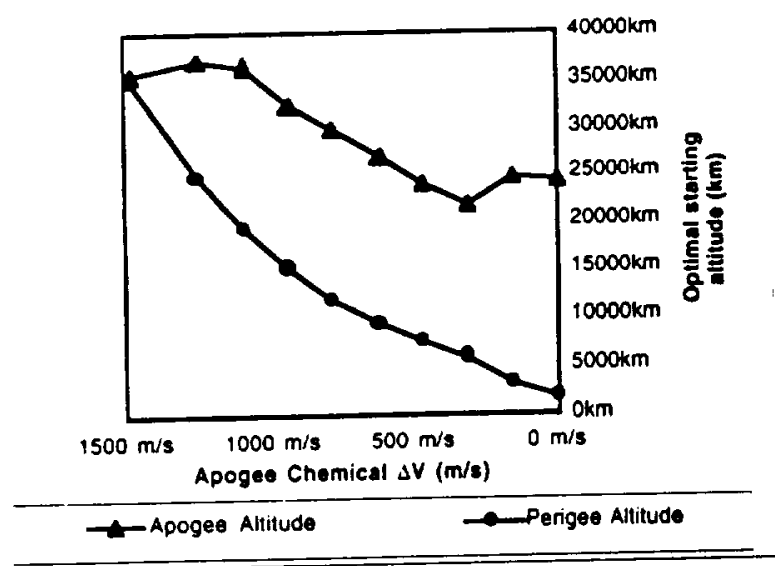

Figure 8 Optimal SEP Starting Orbit vs. Apogee Chemical $\Delta V$.-Sea Launch, Hall $25 \mathrm{~kW}$ Class GEO Satellite

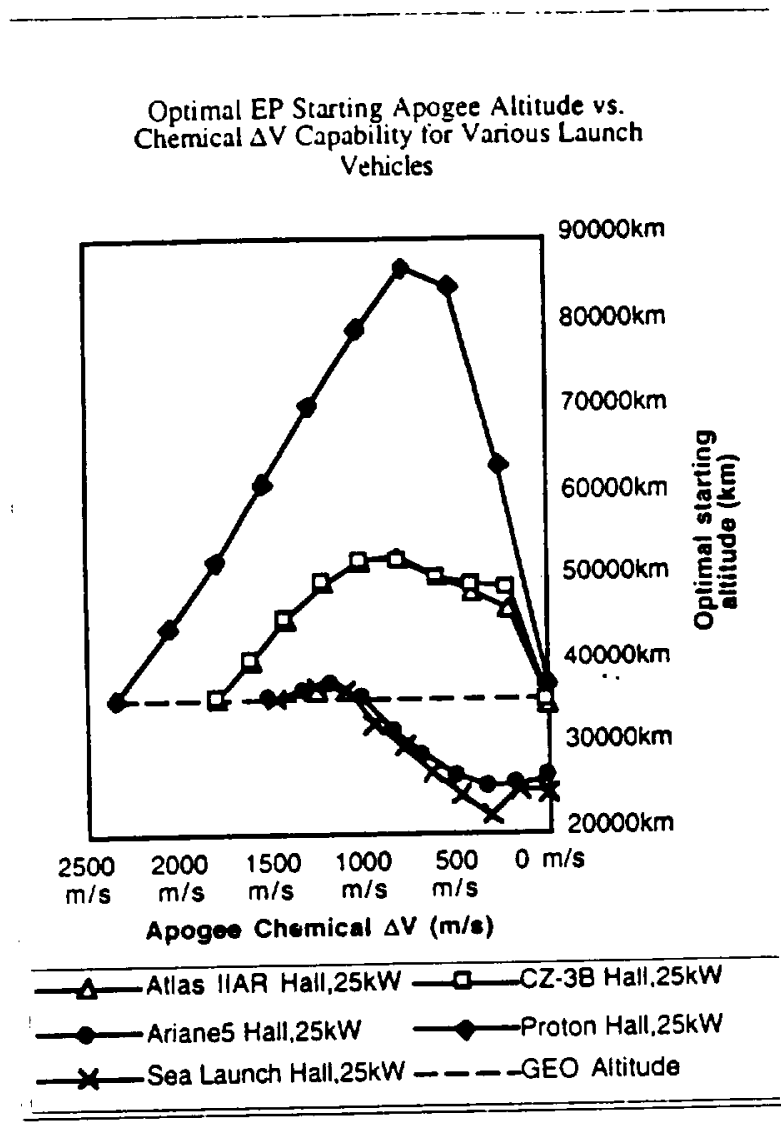

Figure 9 Optimal SEP Starting Orbit Apogee vs. Apogee Chemical $\Delta V$--Various Launch Vehicles, Hall $25 \mathrm{~kW}$ Class GEO Satellite 
Final Net Mass vs SEP Transfer Time: Atlas IIAR

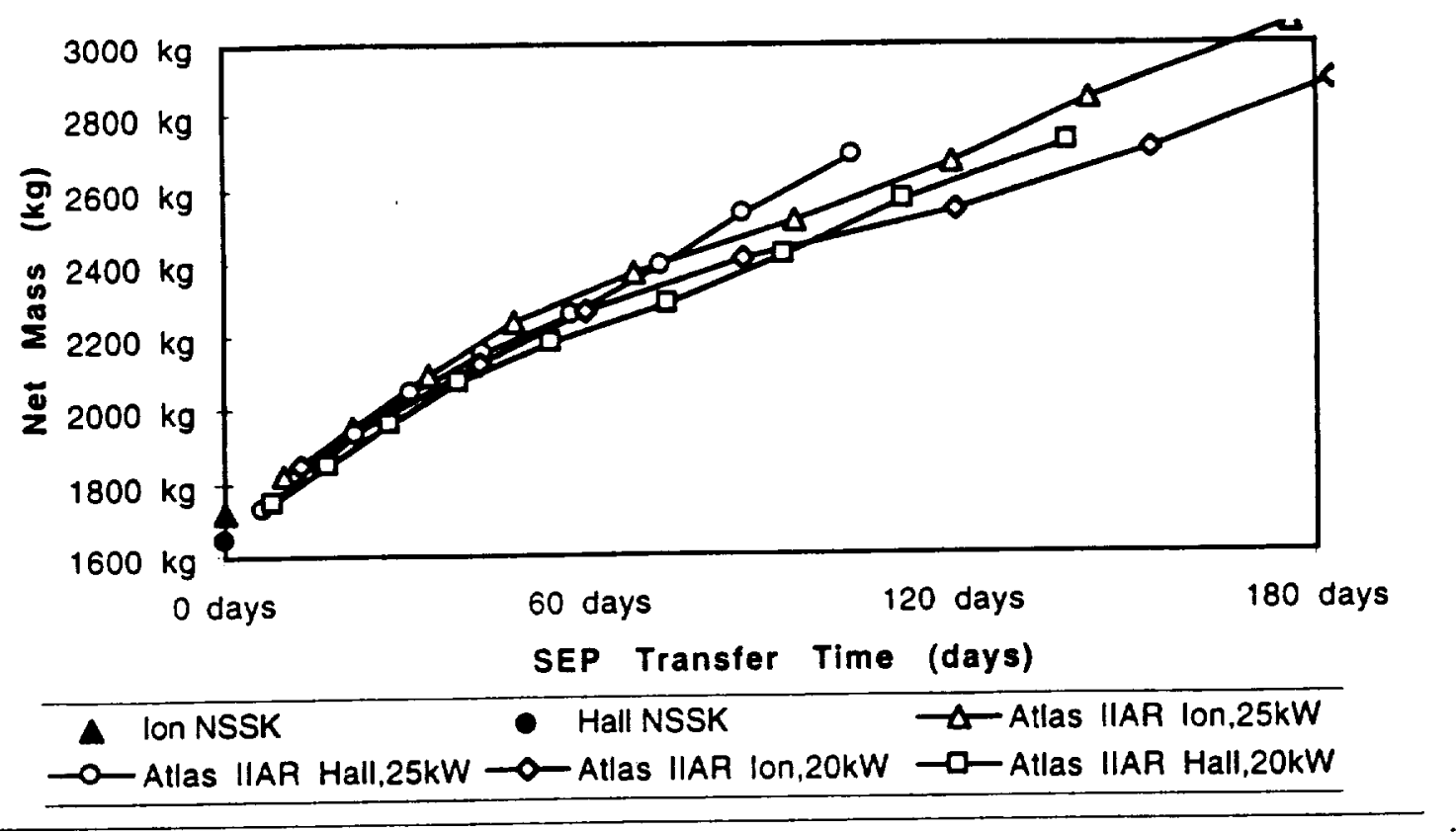

Figure 10 Final Net Mass vs. SEP Transfer Time for the Atlas IIAR

Power Degradation vs SEP Transfer Time: Atlas IIAR

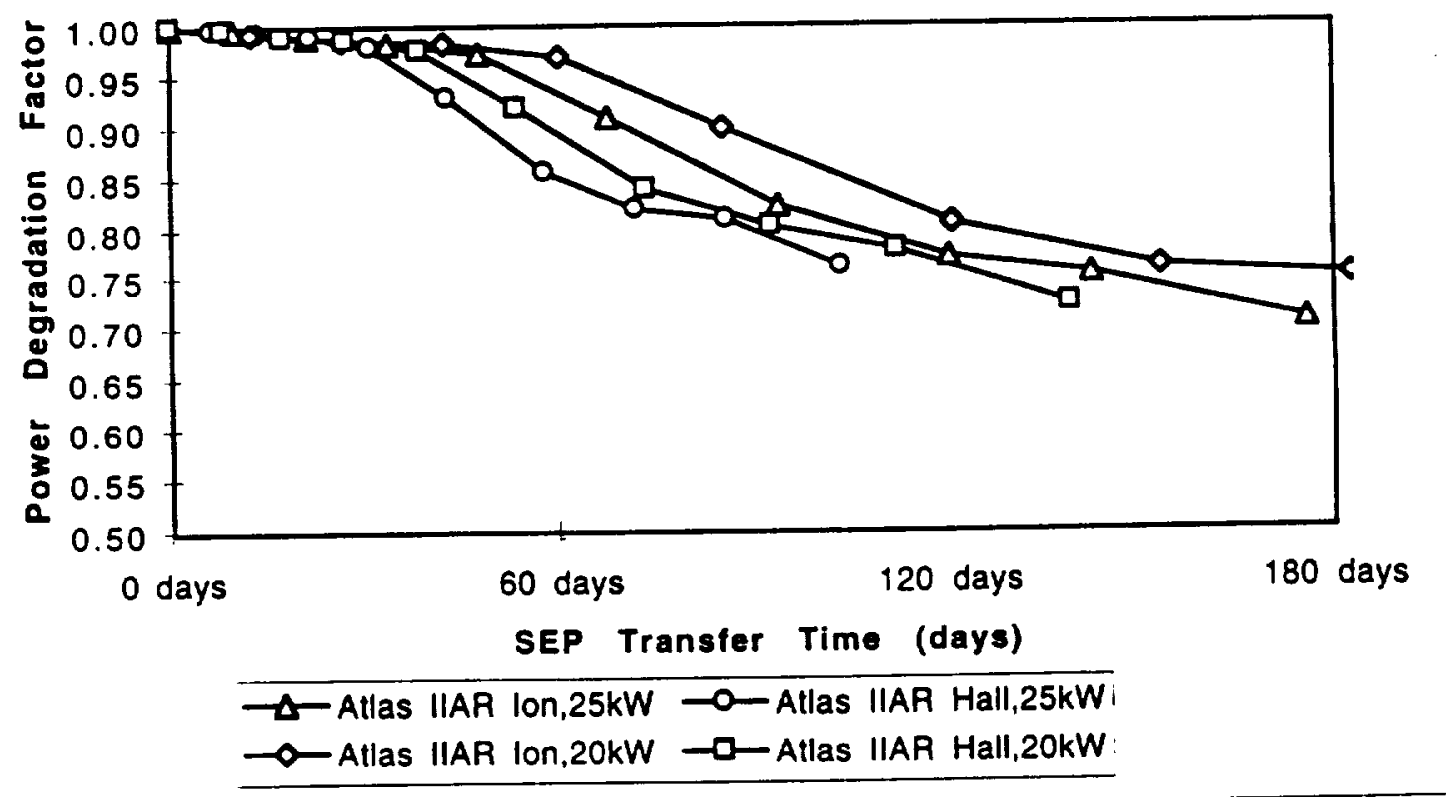

Figure 11 Power Degradation vs. SEP Transfer Time for the Atlas IIAR 
Final Net Mass vs SEP Transfer Time: Atlas IIAR without NSSK

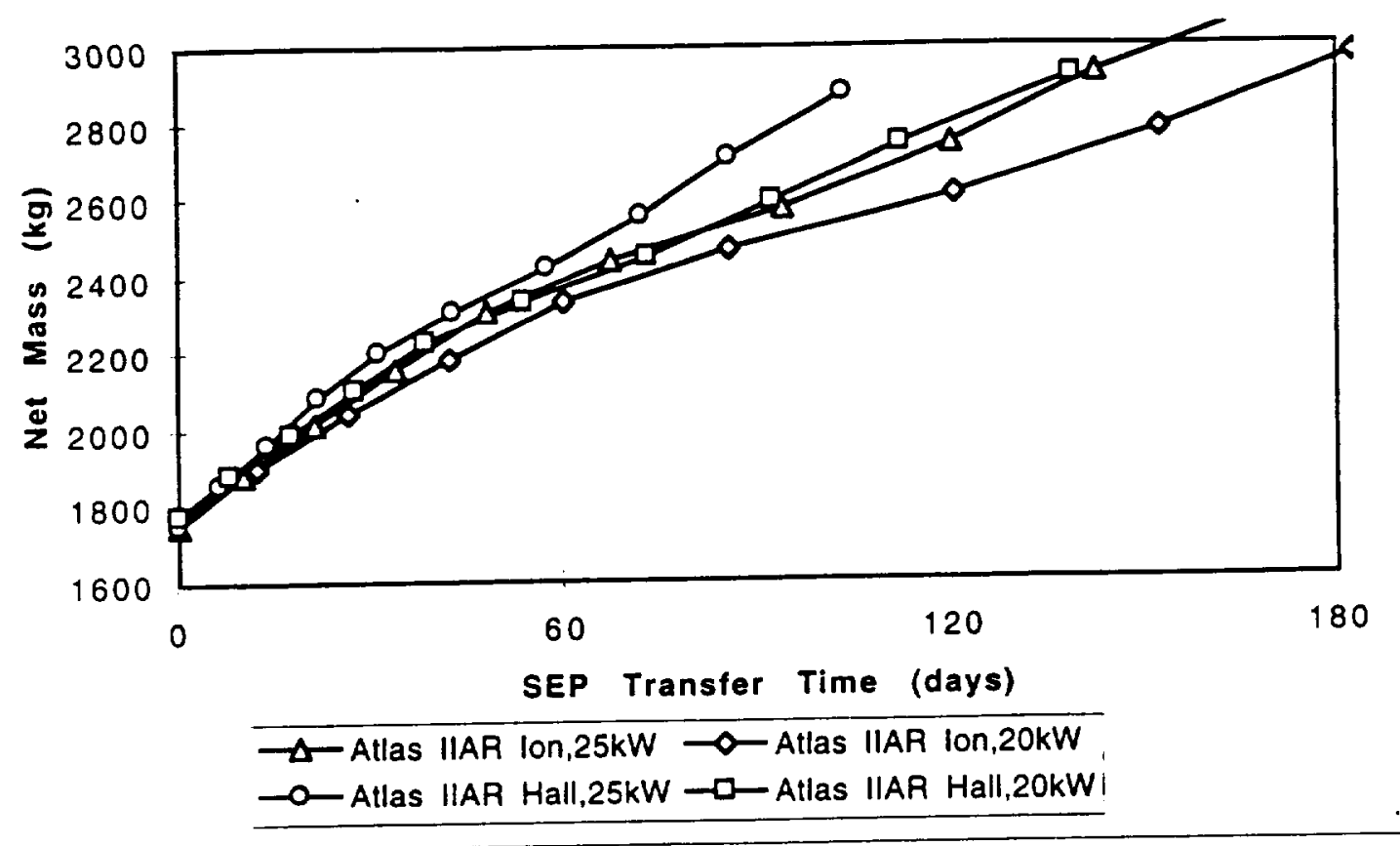

Figure 12 Final Net Mass vs. SEP Transfer Time for the Atlas IIAR without NSSK

Final Net Mass vs SEP Transfer Time: Atlas IIAR and Atlas IIAS

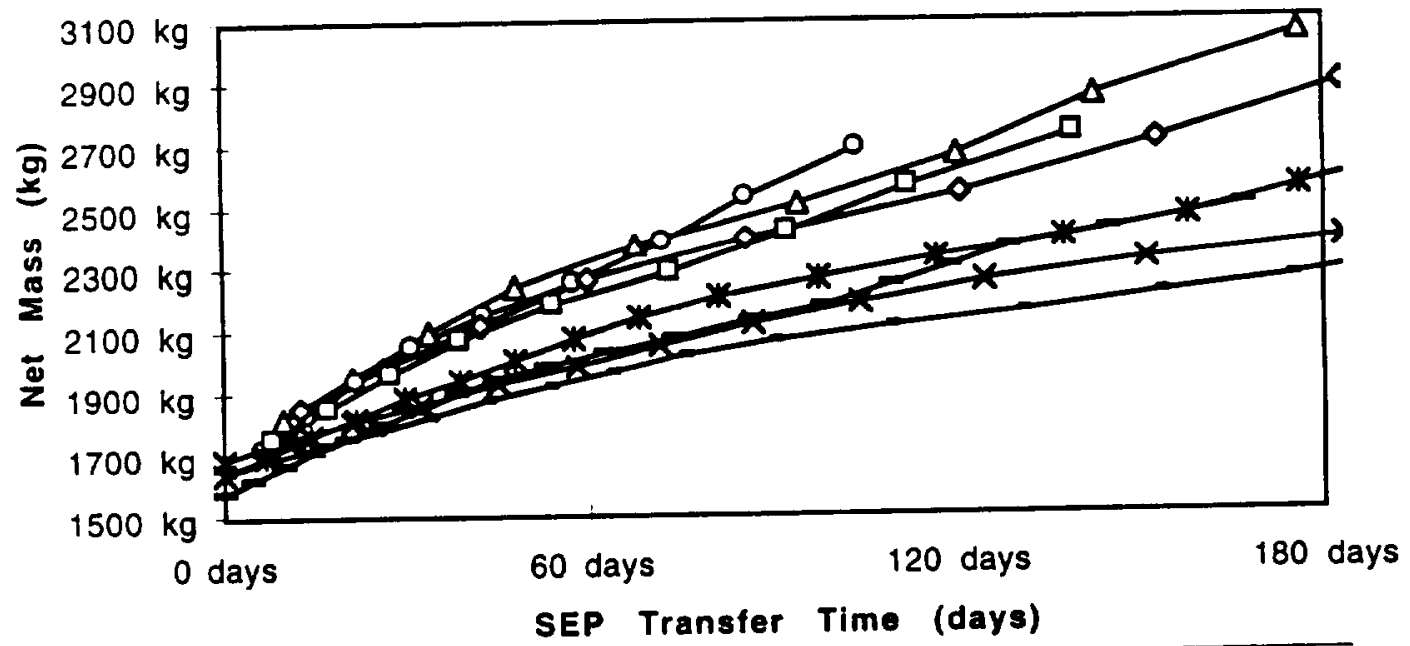

$\triangle$-Atlas IIAR lon, $25 \mathrm{~kW}-0$-Atlas IIAR Hall,25kW - Atlas IIAR lon, $20 \mathrm{~kW}$

$\rightarrow$ Atlas IIAR Hall,20kW - Allas IIAS Hall, 10kW $\rightarrow$ Atlas IIAS lon, $10 \mathrm{~kW}$

- Atlas IIAS Hall, $15 \mathrm{~kW} \rightarrow$ - Atlas IIAS Ion, $15 \mathrm{~kW}$

Figure 13 Final Net Mass vs. SEP Transfer Time for the Atlas IIAR and Atlas IIAS 
Final Net Mass vs SEP Transfer Time: CZ-3B

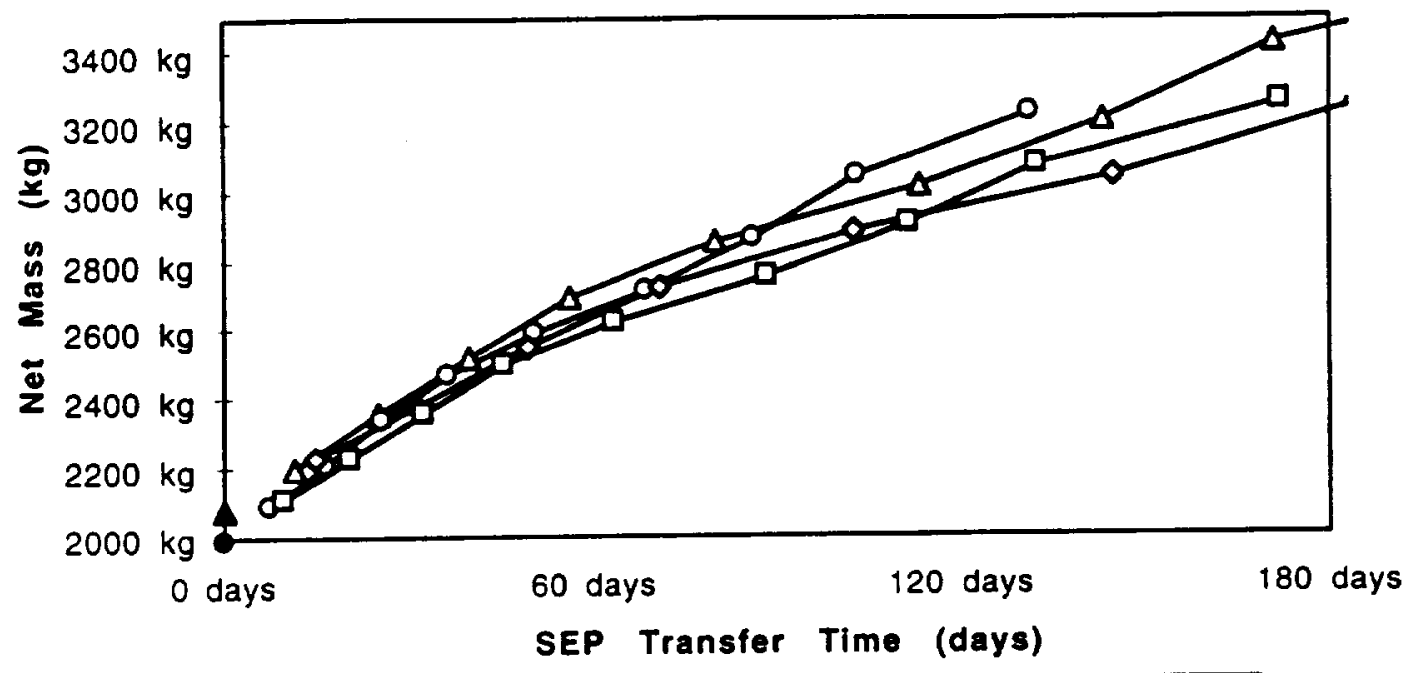

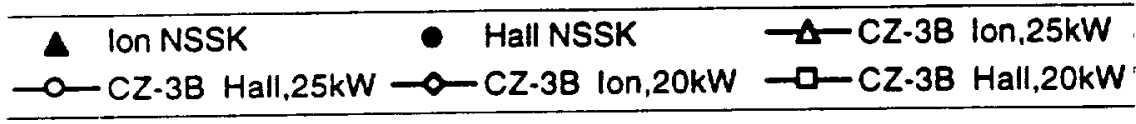

Figure 14 Final Net Mass vs. SEP Transfer Time for the CZ-3B

Power Degradation vs SEP Transfer Time: CZ-3B

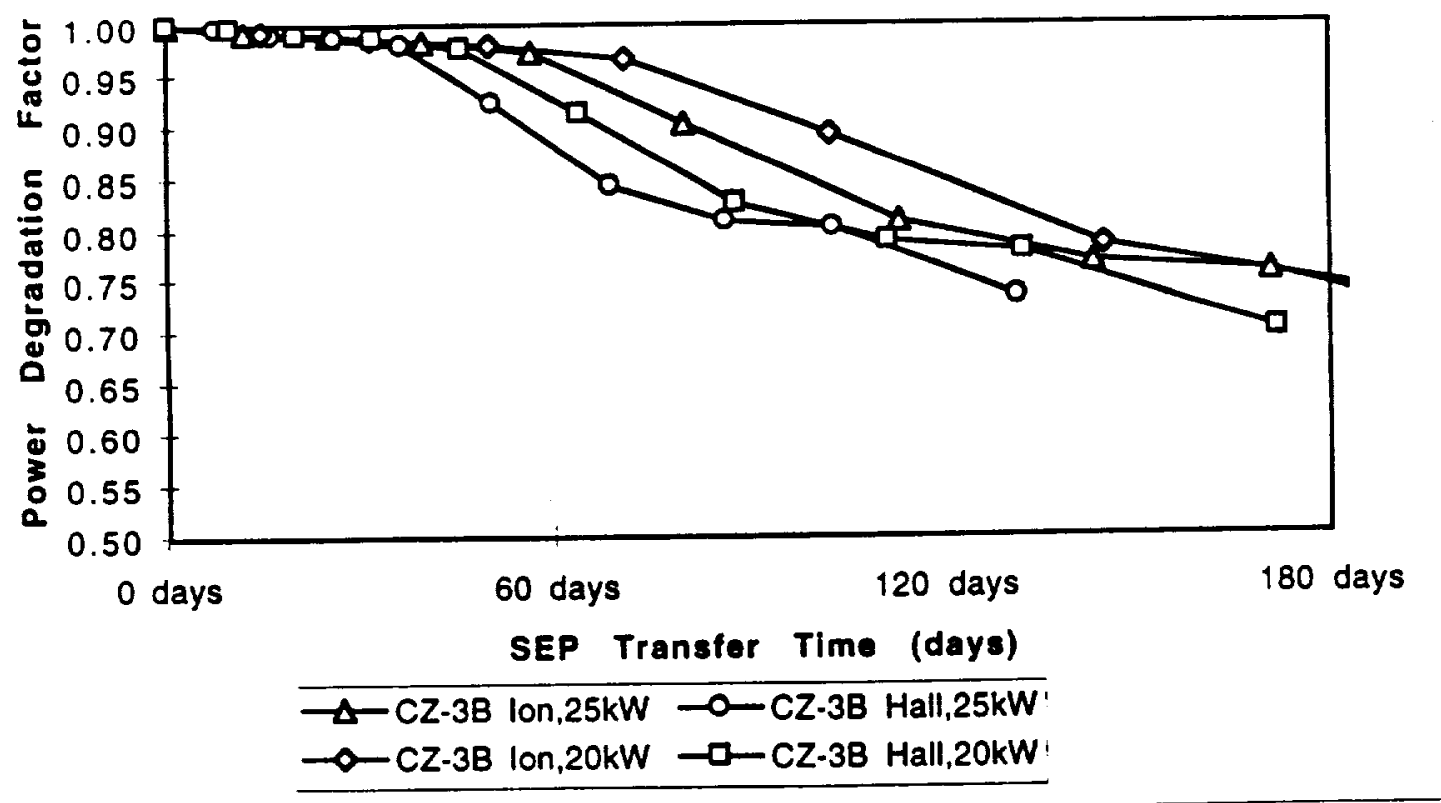

Figure 15 Power Degradation vs. SEP Transfer Time for the CZ-3B 
Final Net Mass vs SEP Transfer Time: Ariane 5

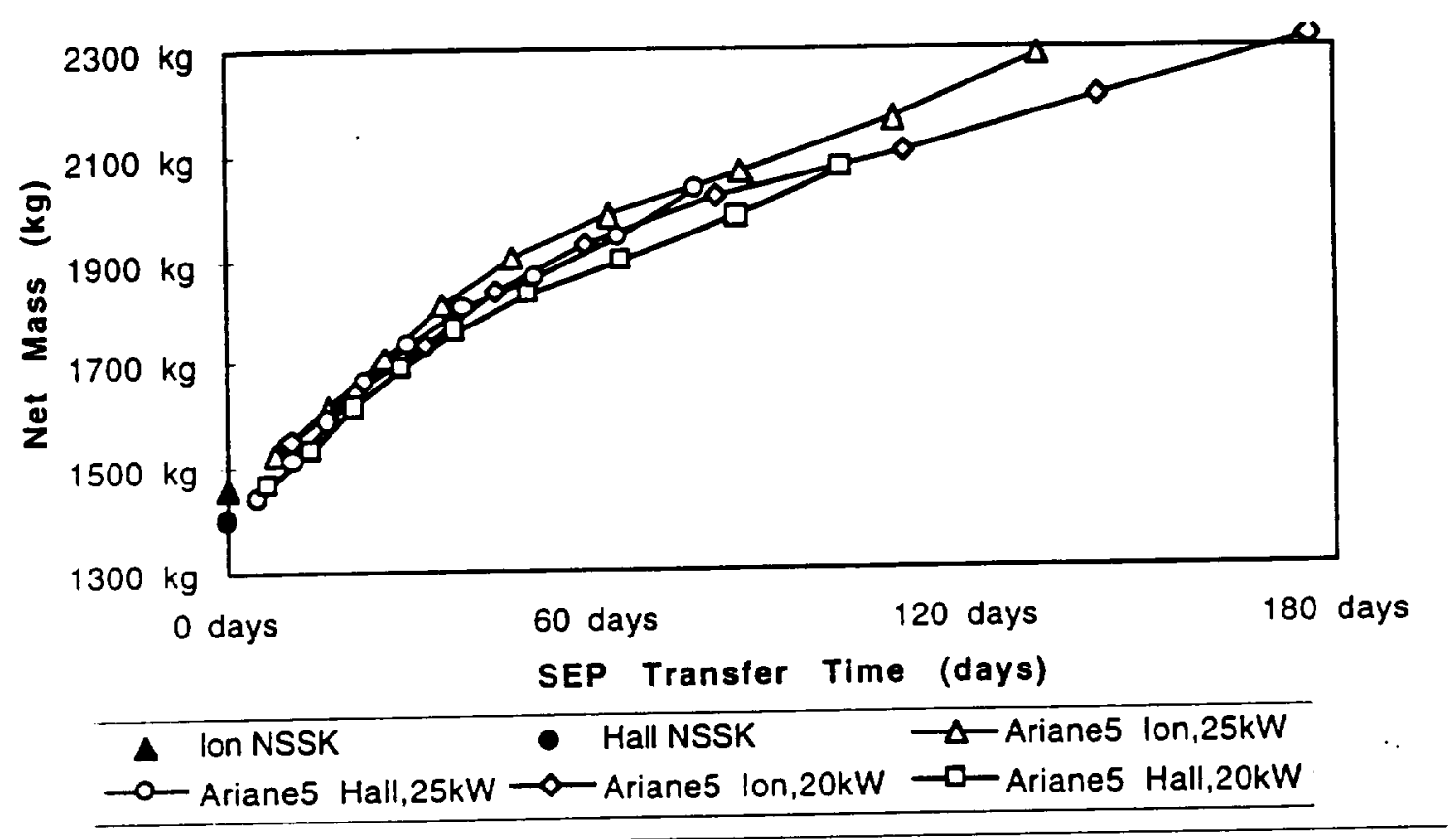

Figure 16 Final Net Mass vs. SEP Transfer Time for the Ariane 5

Power Degradation vs SEP Transfer Time: Ariane 5

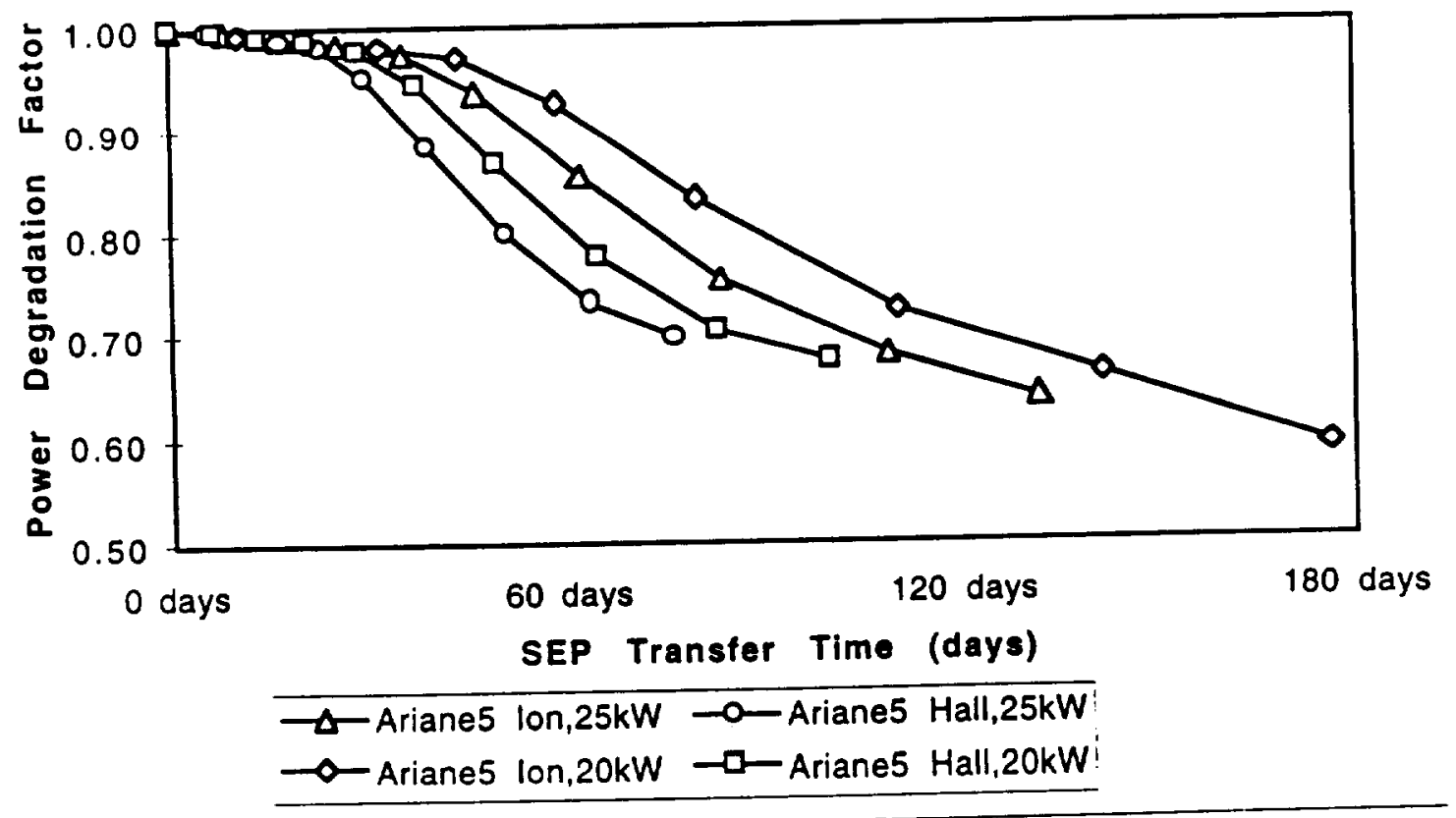

Figure 17 Power Degradation vs. SEP Transfer Time for the Ariane 5 
Final Net Mass vs SEP Transfer Time: Proton

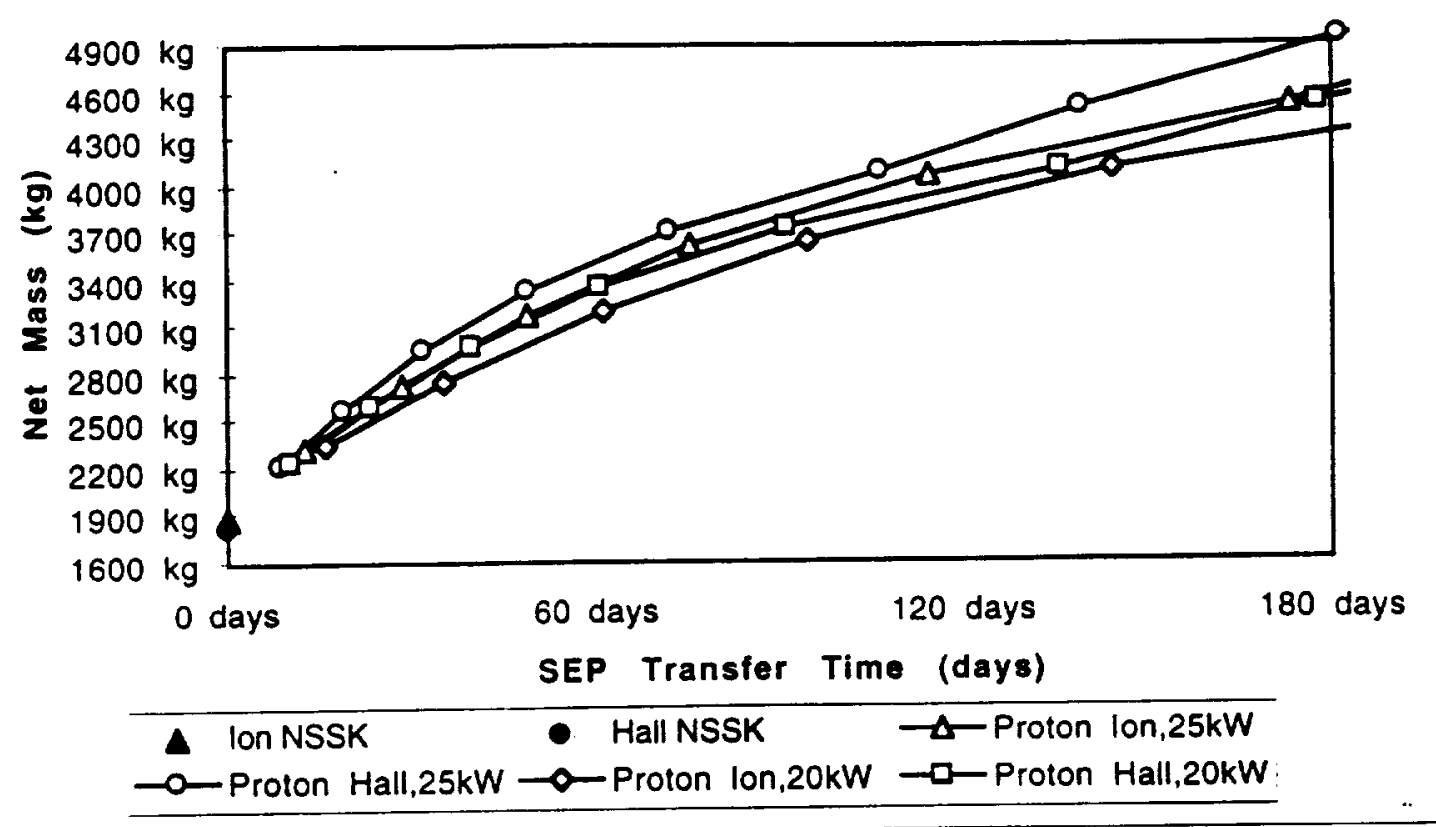

Figure 18 Final Net Mass vs. SEP Transfer Time for the Proton

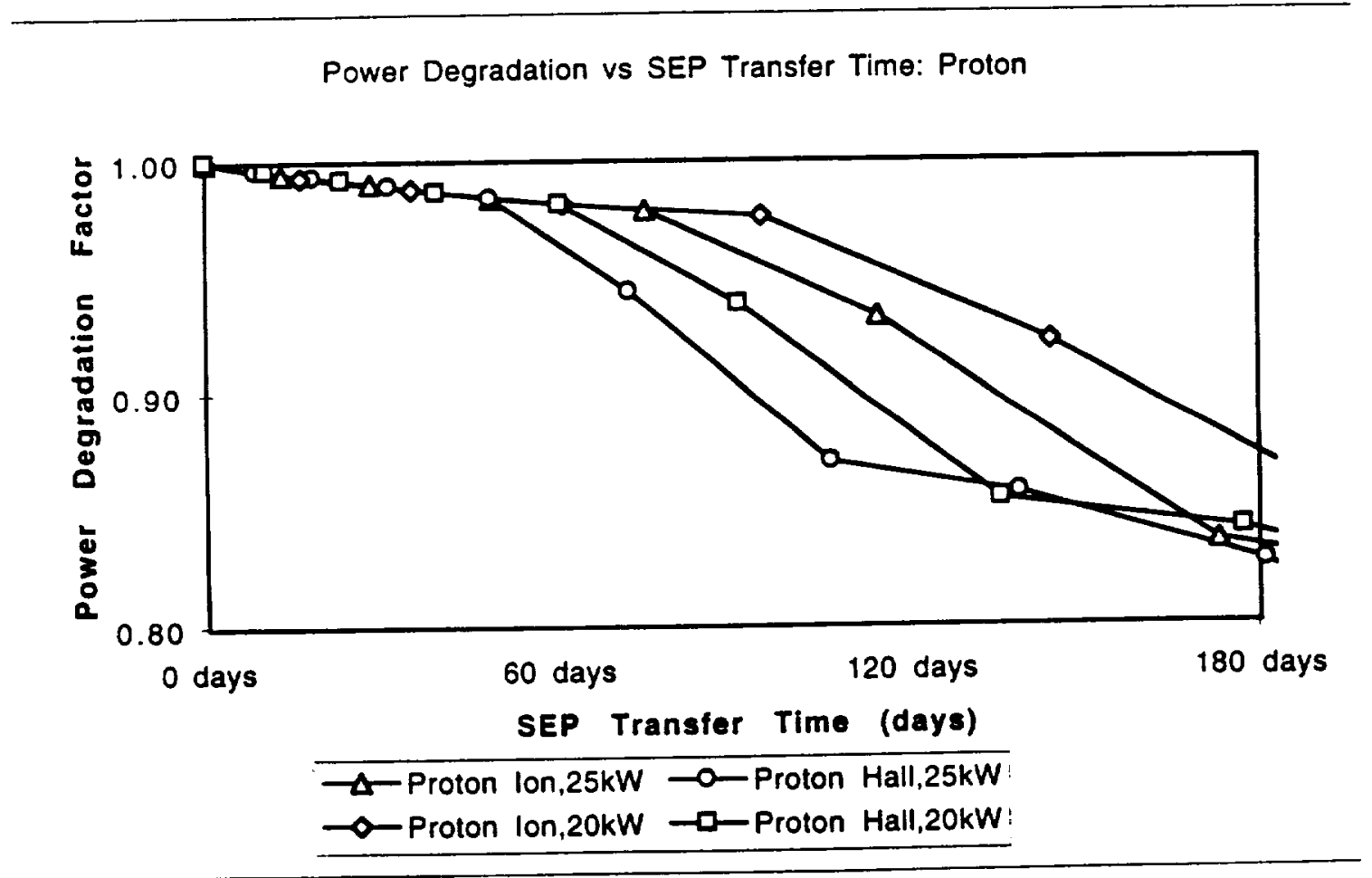

Figure 19 Power Degradation vs. SEP Transfer Time for the Proton 
Final Net Mass vs SEP Transfer Time: Sea Launch

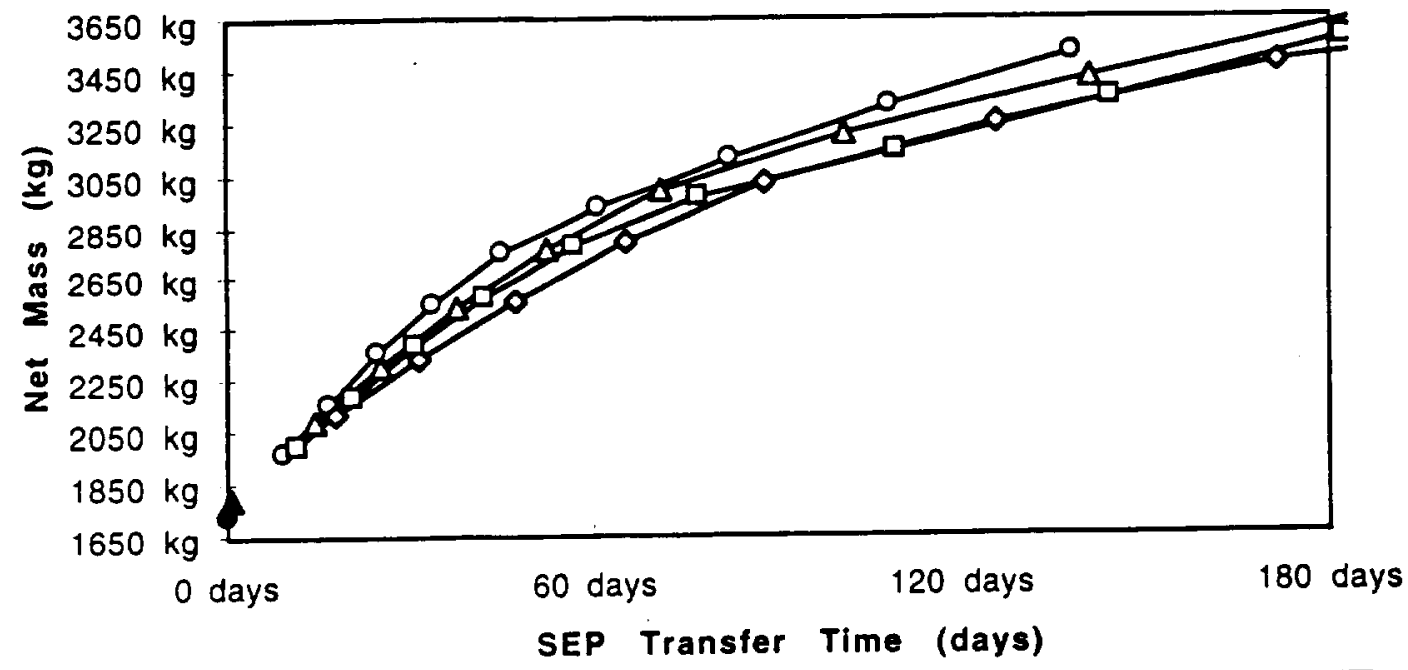

$\triangle$ Ion NSSK

- Hall NSSK $\triangle-$ Sea Launch Ion,25kW

$\rightarrow$ Sea Launch Hall,25kW - Sea Launch Ion,20kW $\rightarrow-$ Sea Launch Hall,20kW:

Figure 20 Final Net Mass vs. SEP Transfer Time for the Sea Launch

Power Degradation vs SEP Transfer Time: Sea Launch

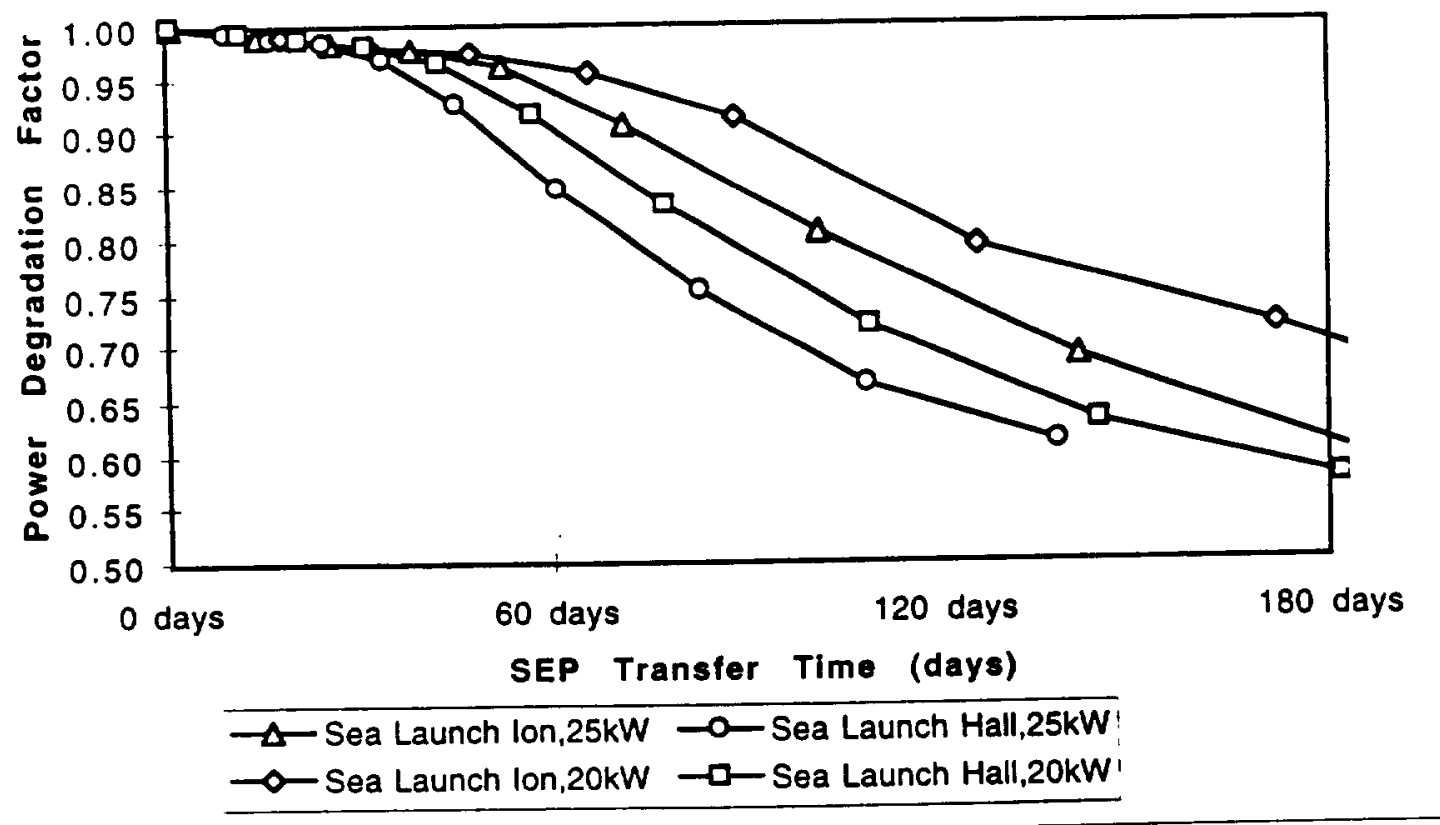

Figure 21 Power Degradation vs. SEP Transfer Time for the Sea Launch 


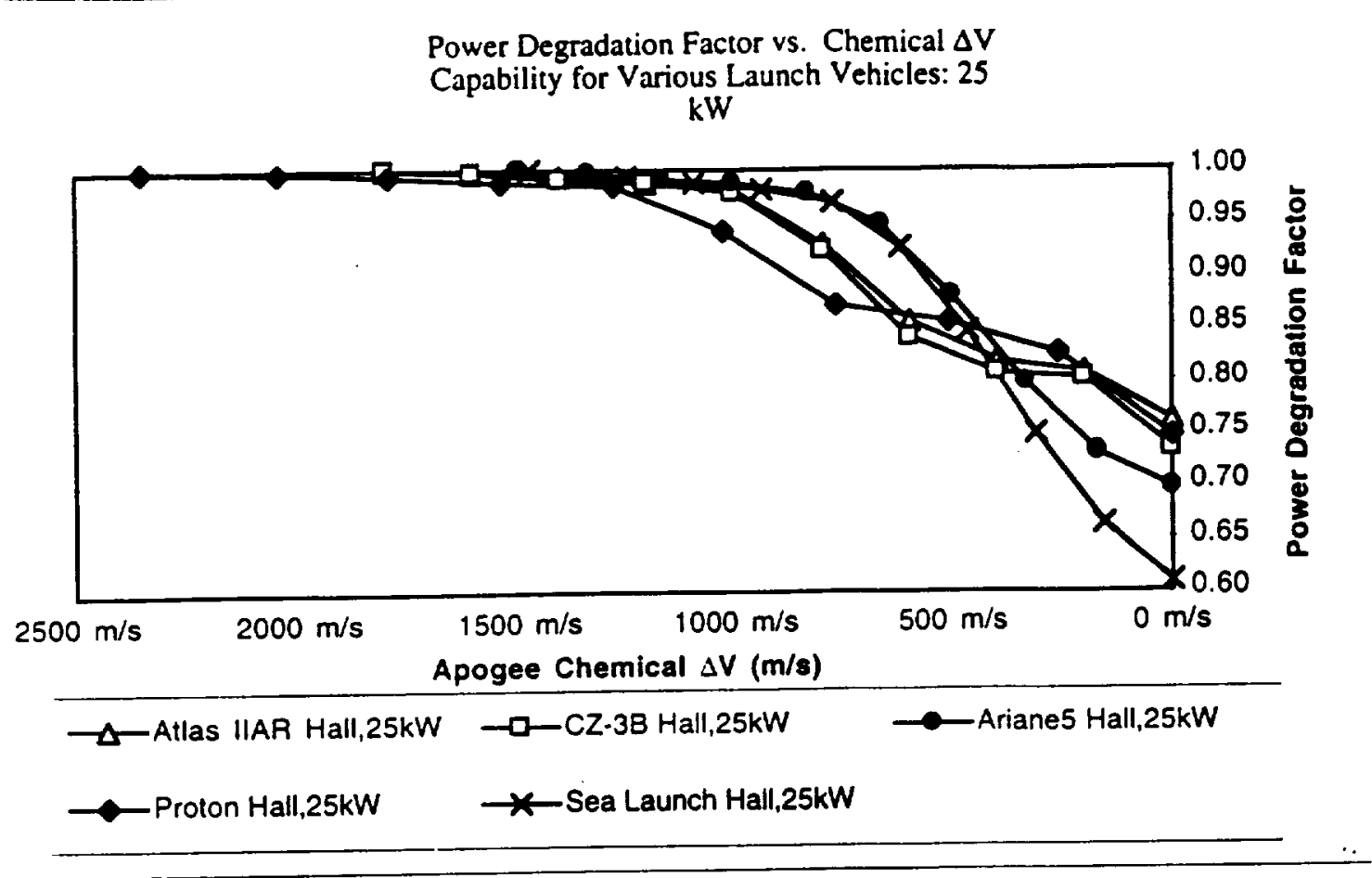

Figure 22 Power Degradation vs. Apogee Chemical $\Delta V$ Capability for various launch vehicles @ $25 \mathrm{~kW}$

Power Degradation Factor vs. Starting SEP Orbit

Perigee Altitude for Various Launch Vehicles: $25 \mathrm{~kW}$

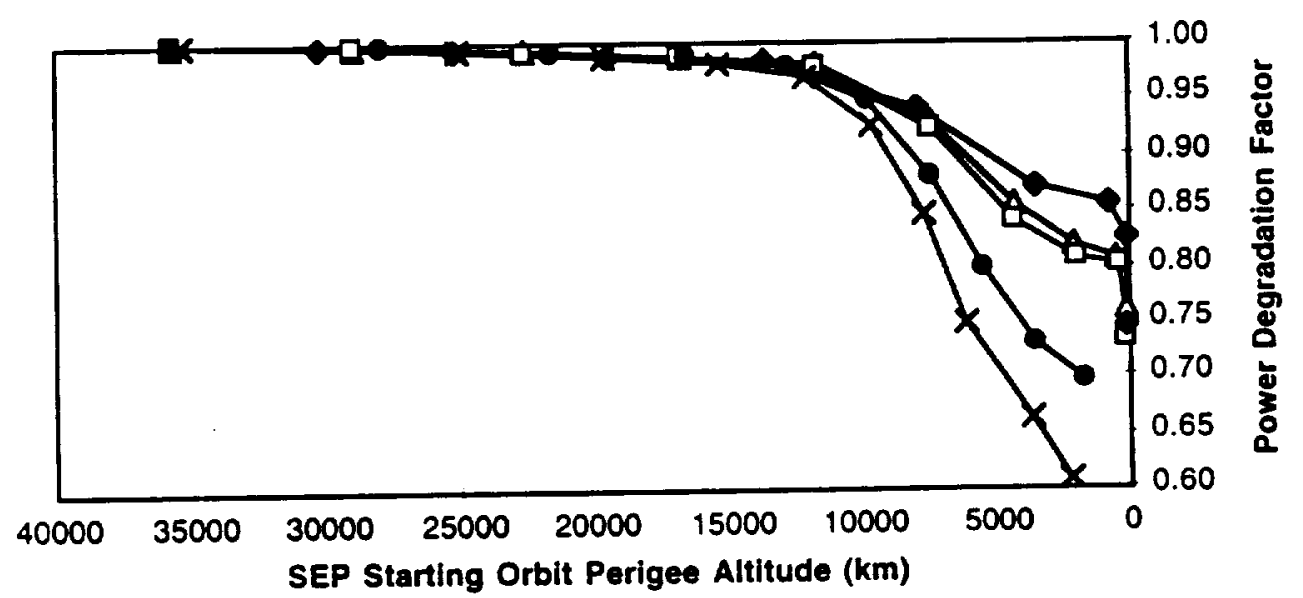

$\rightarrow$ Atlas IIAR Hall,25kW $\rightarrow$-CZ-3B Hall,25kW $\rightarrow$ Ariane5 Hall,25kW

$\longrightarrow$ Proton Hall,25kW $\rightarrow$ Sea Launch Hall,25kW

Figure 23 Power Degradation vs. Apogee Chemical $\Delta V$ Capability for various launch vehicles @ $25 \mathrm{~kW}$ 



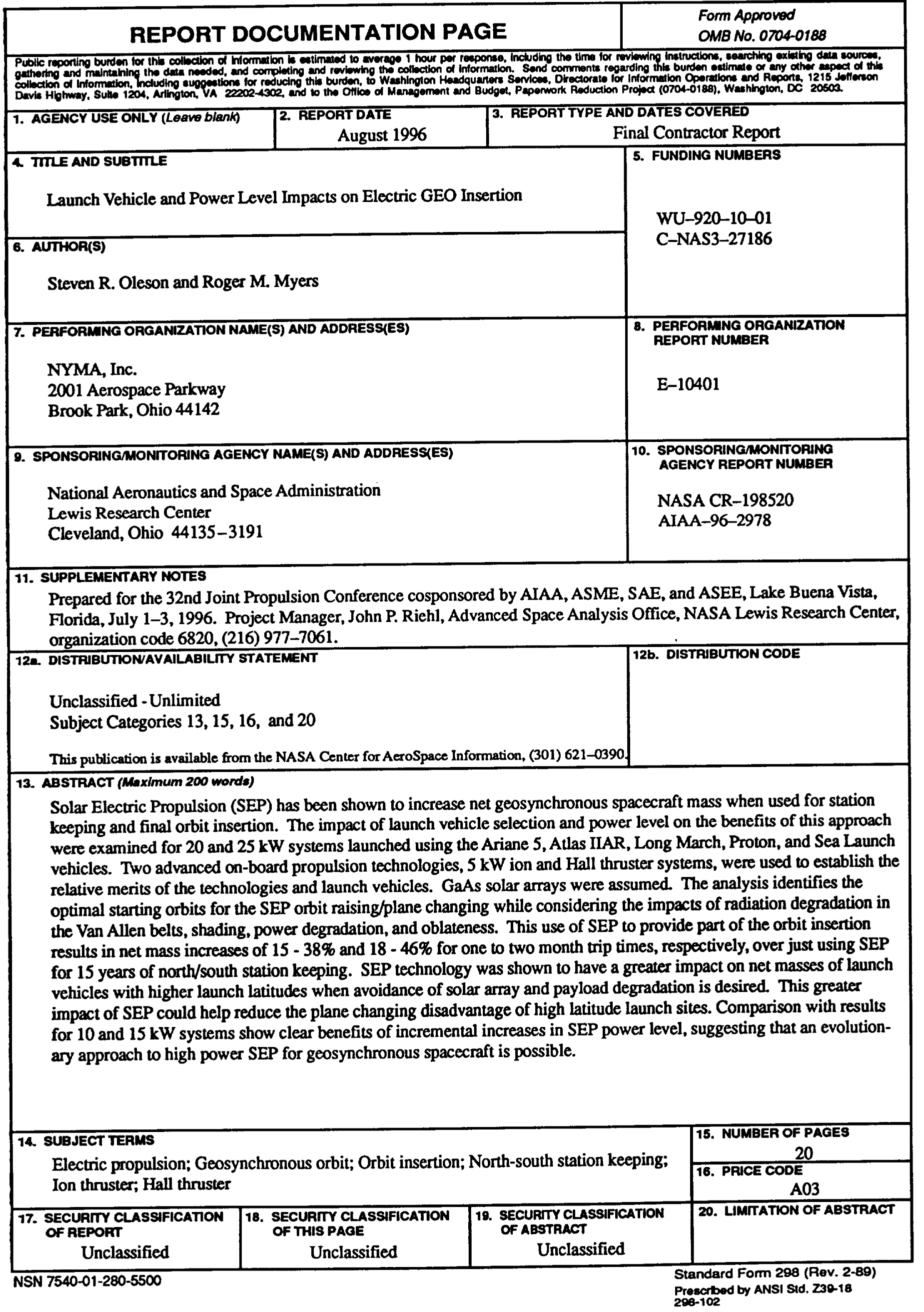





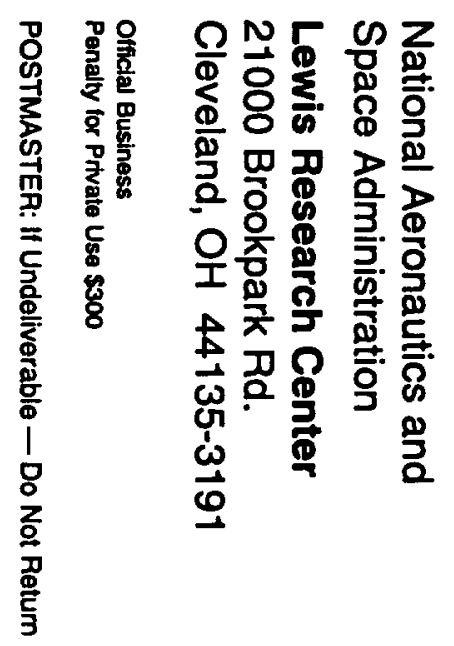

